\title{
Papain-like protease regulates SARS-CoV-2 viral spread and innate immunity
}

https://doi.org/10.1038/s41586-020-2601-5

Received: 30 April 2020

Accepted: 23 July 2020

Published online: 29 July 2020

Check for updates

\section{Donghyuk Shin ${ }^{1,2,3}$, Rukmini Mukherjee ${ }^{1,2}$, Diana Grewe ${ }^{2}$, Denisa Bojkova ${ }^{4}$, Kheewoong Baek $^{5}$, Anshu Bhattacharya ${ }^{1,2}$, Laura Schulz ${ }^{6}$, Marek Widera ${ }^{4}$, Ahmad Reza Mehdipour ${ }^{6}$, Georg Tascher', Paul P. Geurink ${ }^{7}$, Alexander Wilhelm ${ }^{4,8}$, Gerbrand J. van der Heden van Noort ${ }^{7}$, Huib Ovaa ${ }^{7,13}$, Stefan Müller', Klaus-Peter Knobeloch ${ }^{9}$, Krishnaraj Rajalingam ${ }^{10}$, Brenda A. Schulman ${ }^{5}$, Jindrich Cinatl ${ }^{4}$, Gerhard Hummer ${ }^{6,11}$, Sandra Ciesek ${ }^{4,8,12}$ \& Ivan Dikic ${ }^{1,2,3,12 \bowtie ~}$}

\begin{abstract}
The papain-like protease PLpro is an essential coronavirus enzyme that is required for processing viral polyproteins to generate a functional replicase complex and enable viral spread ${ }^{1,2}$. PLpro is also implicated in cleaving proteinaceous post-translational modifications on host proteins as an evasion mechanism against host antiviral immune responses ${ }^{3-5}$. Here we perform biochemical, structural and functional characterization of the severe acute respiratory syndrome coronavirus 2 (SARS-CoV-2) PLpro (SCoV2-PLpro) and outline differences with SARS-CoV PLpro (SCoV-PLpro) in regulation of host interferon and NF-KB pathways. SCoV2-PLpro and SCoV-PLpro share $83 \%$ sequence identity but exhibit different host substrate preferences; SCoV2-PLpro preferentially cleaves the ubiquitin-like interferon-stimulated gene 15 protein (ISG15), whereas SCoV-PLpro predominantly targets ubiquitin chains. The crystal structure of SCoV2-PLpro in complex with ISG15 reveals distinctive interactions with the amino-terminal ubiquitin-like domain of ISG15, highlighting the high affinity and specificity of these interactions. Furthermore, upon infection, SCoV2-PLpro contributes to the cleavage of ISG15 from interferon responsive factor 3 (IRF3) and attenuates type I interferon responses. Notably, inhibition of SCoV2-PLpro with GRL-0617 impairs the virus-induced cytopathogenic effect, maintains the antiviral interferon pathway and reduces viral replication in infected cells. These results highlight a potential dual therapeutic strategy in which targeting of SCoV2-PLpro can suppress SARS-CoV-2 infection and promote antiviral immunity.
\end{abstract}

The novel coronavirus SARS-CoV-2 is the cause of the current worldwide outbreak of the respiratory disease coronavirus disease 2019 (COVID-19) ${ }^{6}$. COVID-19 generally has less severe symptoms and a lower case-fatality rate but is transmitted more rapidly compared with the related SARS-CoV, which caused the SARS outbreak in 2003. The SARS-CoV-2 genome shares high sequence identity with SARS-CoV ${ }^{7,8}$. Both viruses critically rely on the activity of viral proteases: the main protease (Mpro, also known as 3CLpro or non-structural protein 5 (nsp5)) and the papain-like protease (PLpro, the protease domain of nsp3) to generate a functional replicase complex and enable viral spread ${ }^{1,2}$. SCoV-PLpro cleaves ubiquitin and ISG15, known regulators of host innate immune pathways, and inhibition of SCoV-PLpro has been shown to block SARS-CoV replication ${ }^{3-5}$.

\section{SARS-CoV-2 PLpro preferentially cleaves ISG15}

SCoV-PLpro and SCoV2-PLpro are closely related and diverge from Middle East respiratory syndrome (MERS) coronavirus PLpro (MERS-PLpro) (Extended Data Fig. 1a).Purified SCoV-PLpro and SCoV2-PLpro exhibit differences in their substrate preferences, as revealed by their cleavage of ubiquitin or ISG15 from substrates in HeLa cells treated with interferon- $\alpha$ (IFN- $\alpha)$ (Extended Data Fig. 1b). SCoV-PLpro strongly reduced the appearance of ubiquitinated substrates, with a lesser effect on ISGylated substrates, whereas SCoV2-PLpro preferentially reduced appearance of ISG15-conjugated (ISGylated) protein substrates (Extended Data Fig. 1b).

We next used activity-based probes, namely a highly reactive propargylamide (Prg) 'warhead', which forms a covalent bond with

${ }^{1}$ Institute of Biochemistry II, Faculty of Medicine, Goethe University, Frankfurt, Germany. ${ }^{2}$ Buchmann Institute for Molecular Life Sciences, Goethe University, Frankfurt, Germany. ${ }^{3}$ Max Planck Institute of Biophysics, Frankfurt, Germany. ${ }^{4}$ Institute of Medical Virology, University Hospital Frankfurt, Frankfurt, Germany. ${ }^{5}$ Department of Molecular Machines and Signaling, Max Planck

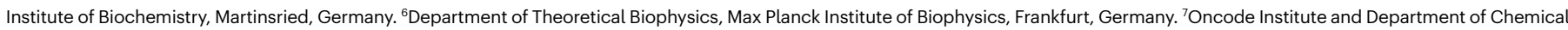

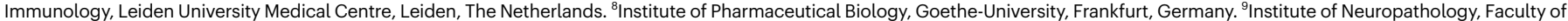
Medicine, University of Freiburg, Freiburg, Germany. ${ }^{10} \mathrm{Cell}$ Biology Unit, University Medical Center of the Johannes Gutenberg University Mainz, Mainz, Germany. ${ }^{11}$ Institute of Biophysics,

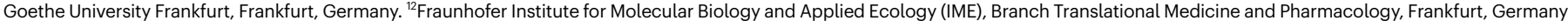
${ }^{13}$ Deceased: Huib Ovaa. ${ }^{\bowtie}$ e-mail: dikic@biochem2.uni-frankfurt.de 


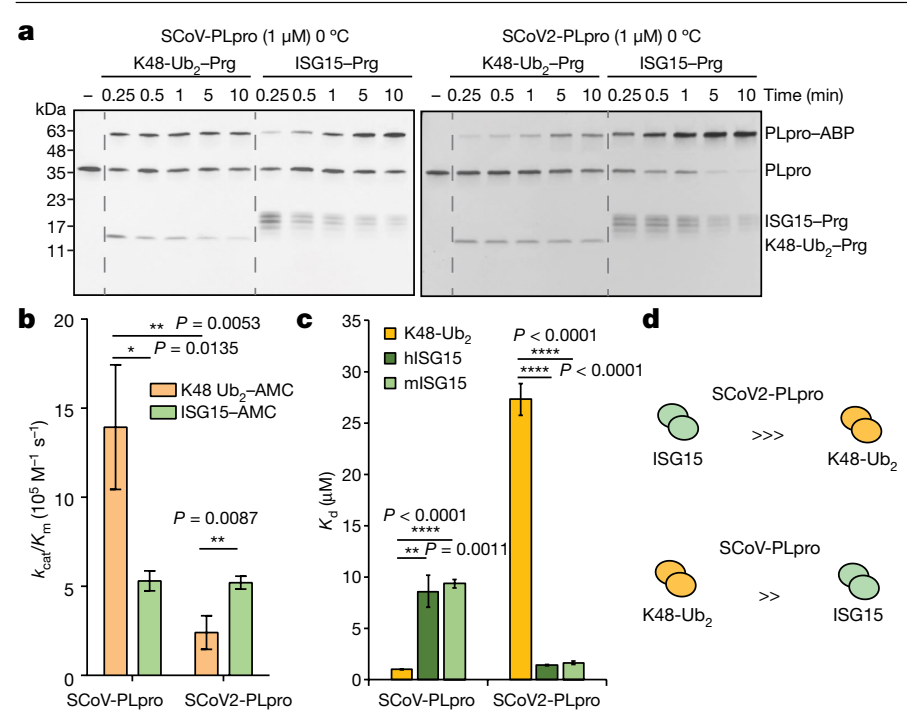

Fig. 1 | DeISGylating and deubiquitylating activities of SCoV-PLpro and SCoV2-PLpro.a, SCoV-PLpro (left) or SCoV2-PLpro (right) were incubated with indicated Prg probes. Experiments were repeated three times independently with similar results. b, Catalytic efficiency $\left(k_{\text {cat }} / K_{\mathrm{m}}\right)$ of SCoV2-PLpro and SCoV-PLpro cleavage of K48-Ub $\mathrm{U}_{2}$-AMC or ISG15-AMC.c, Dissociation constant $\left(K_{\mathrm{d}}\right)$ of SCoV2-PLpro and SCoV-PLpro. Data in c, d, are mean \pm s.d. or mean \pm s.e.m. $\left(n=3\right.$ independent experiments). ${ }^{*} P<0.05,{ }^{* *} P<0.01$, ${ }^{* * * *} P<0.0001$; two-tailed paired $t$-test. $\mathbf{d}$, Schematic representation of substrate specificity of SCoV2-PLpro (red) and SCoV-PLpro (blue). The preferred substrate is shown on the left.

catalytic cysteines, and a 7-amido-4-methylcoumarine (AMC) probe, which emits fluorescence upon cleavage, enabling the monitoring of the kinetics of the protease activity ${ }^{9-13}$. SCoV2-PLpro preferentially reacted with the ISG15-Prg probe, but showed weak activity towards K48-linked di-ubiquitin ( $\left.\mathrm{K} 48-\mathrm{Ub}_{2}\right)$ and Nedd8, and no activity towards SUMO-based Prg probes (Fig. 1a, Extended Data Fig. 1c). SCoV-PLpro showed highest reactivity with $\mathrm{K} 48-\mathrm{Ub}_{2}$ Prg probes, and less reactivity towards the ISG15-Prg probe (Fig. 1a, Extended Data Fig. 1c). This substrate preference was further confirmed using competition assays with increasing doses of K48-Ub $\mathrm{U}_{2}$ (Extended Data Fig. 1d, e). In the reaction with SCoV-PLpro, $\mathrm{K} 48-\mathrm{Ub}_{2}$ effectively competed with both ISG15-Prg and ISG15-AMC, whereas competitive displacement was much less effective with SCoV2-PLpro. We also examined the catalytic efficiency (turnover number $\left(k_{\text {cat }}\right) /$ Michaelis constant $\left.\left(K_{\mathrm{m}}\right)\right)$ of both PLpro proteins (Fig. 1b, Extended Data Table 2), which indicated that SCoV2-PLpro cleaved AMC from ISG15-AMC more efficiently than from $\mathrm{K} 48-\mathrm{Ub}_{2}-\mathrm{AMC}$, whereas SCoV-PLpro cleaved AMC from K48-Ub more efficiently. Of note, the apparent catalytic efficiencies $\left(k_{\mathrm{cat}} / K_{\mathrm{m}}\right)$ of the two PLpro enzymes towards ISG15 were similar, but SCoV2-PLpro showed slightly higher specificity towards ISG15 (indicated by lower $K_{\mathrm{m}}$ ) (Fig. 1b, Extended Data Table 2). Consistently, SCoV2-PLpro bound ISG15 with a 20-fold higher affinity compared with $\mathrm{K} 48-\mathrm{Ub}_{2}$, whereas SCoV-PLpro bound $\mathrm{K} 48-\mathrm{Ub}_{2}$ with a 10 -fold higher affinity compared with both mouse and human ISG15 ${ }^{14}$ (Fig. 1c, Extended Data Table 3). Indeed, the deISGylase activity of SCoV2-PLpro towards Prg- or AMC-based substrates, was similar to or higher than that of mouse USP18, a specific deISGylase ${ }^{12,15}$ (Extended Data Fig. 1f, g). Both PLpro enzymes also displayed weak deneddylation activity towards hyperneddylated CUL1, a common feature of deneddylases such as DEN1 (Extended Data Fig. 1c, h, i). Together, these results indicate that SCoV2-PLpro preferentially cleaves ISG15 from substrates over ubiquitin chains and Nedd8 in vitro, whereas SCoV-PLpro targets ubiquitin chains and, to a lesser extent, ISG15 and Nedd8 (Fig. 1d).

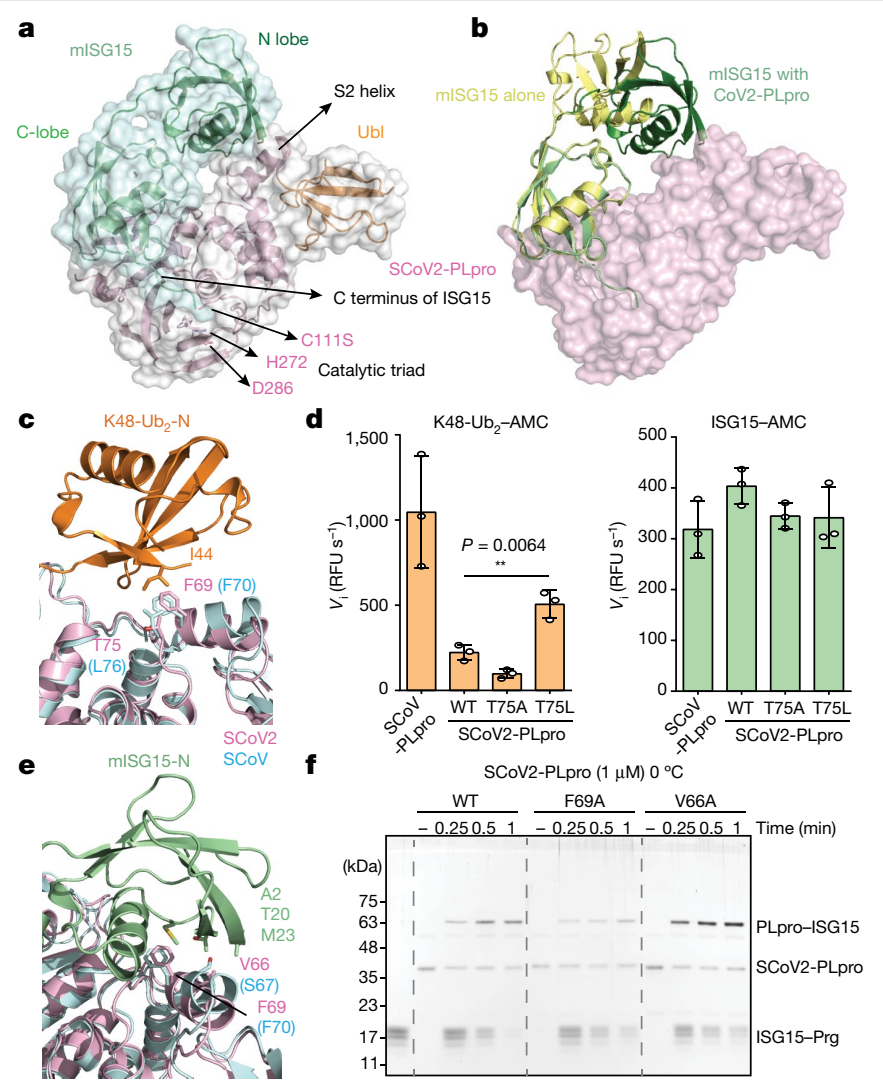

Fig. 2 |Structural analysis of SARS-CoV-2 PLpro in complex with full length ISG15. a, Crystal structure of SARS-CoV-2 PLpro(C111S) in complex with mouse ISG15. The C-terminal glycine of ISG15 and cataly tic triad of SCoV2-PLpro are highlighted as stick model. The ubiquitin like domain ( $\mathrm{Ubl}$ ) is coloured orange. b. Comparison of unbound form of ISG15 with ISG15 in complex with SCoV2-PLpro. c, Comparison of N-terminal half of K48-linked di-ubiquitin (K48 $\mathrm{Ub}_{2}-\mathrm{N}$ )-SCoV-PLpro complex structure (PDB ID: 5E6J) with ISG15-SCoV2-PLpro. Residues forming hydrophobic interactions are highlighted as stick model. d, Initial velocity $\left(V_{\mathrm{i}}\right)$ of AMC release from AMC probes $\left(\mathrm{K} 48-\mathrm{Ub}_{2}-\mathrm{AMC}\right.$ and ISG15-AMC) with the indicated wild-type (WT) and mutant PLpro. Data are mean \pm s.d. $\left(n=3\right.$ independent experiments). ${ }^{* *} P<0.01$; two-tailed paired $t$-test. e, Comparison of N-terminal half of mouse ISG15 (ISG15-N) and SCoV2-PLpro and SCoV-PLpro (PDB ID:5E6J). Residues forming hydrophobic interactions are highlighted as stick model.f, ISG15-Prg was incubated with wild type and mutant SCoV2-PLpro. Experiments were repeated three times independently with similar results.

\section{Structural analysis of SCoV2-PLpro-ISG15}

To gain insight into the molecular basis underlying specificity of SCoV2-PLpro-ISG15, we determined the crystal structure of a complex comprising SCoV2-PLpro(C111S) and mouse ISG15 (Fig. 2a, Extended Data Fig. 2a). Notably, ISG15 displays two tandem ubiquitin-like folds. The overall assembly of SCoV2-PLpro and the two ISG15 domains was similar to the complex of MERS-PLpro with human ISG15 complex ${ }^{16}$ (Protein Data Bank (PDB) ID: 6BI8; Extended Data Fig. 2a). The catalytic cysteine residue is also conserved in SARS (Extended Data Fig. 2b). Compared with the crystal structure of ISG15 in isolation (PDB ID:5TLA) ${ }^{17}$, the $\mathrm{N}$-terminal half of ISG15 is rotated by almost $90^{\circ}$ and rests on the S2 helix of SCoV2-PLpro (Fig. 2b). The structure of SCoV-PLpro in complex with the $C$ terminus of mouse ISG15 (PDB ID: 5 TL7) ${ }^{17}$ showed that SCoV-PLpro and SCoV2-PLpro share the same binding mode to the C-lobe of mouse ISG15 (Extended Data Fig. 2c). We next compared the structure of the SCoV2-PLpro-ISG15 complex to that of SCoV-PLpro bound to K48-Ub in which the proximal ubiquitin is linked to the catalytic site. The main difference between these complexes is an interaction remote from the 

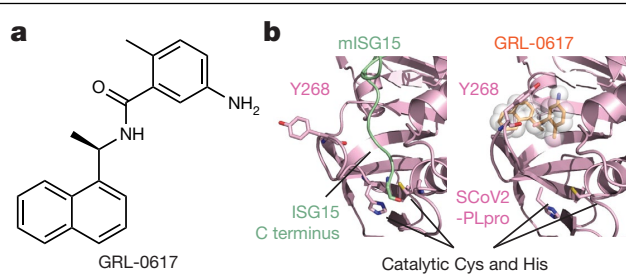

Fig. 3 | Effect of GRL-0617 on SCoV2-PLpro. a, Structure of GRL-0617.b, Comparison of ISG15-bound (left) and GRL-0617 bound (right) structure. Blocking loop 2 (BL2 loop) of SCoV2-PLpro is modelled on the basis of GRL-0617 bound SCoV-PLpro and SCoV2-PLpro structures (PDB ID:3E9S ${ }^{18}$ and 6W9C).

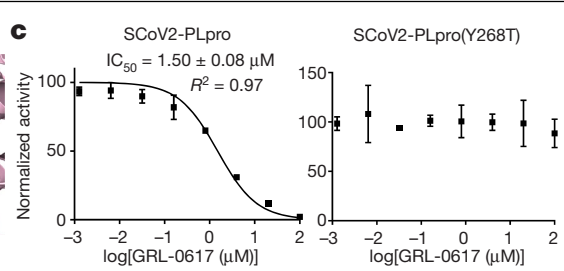

GRL-0617-interacting Tyr268 and catalytic Cys. His residues are highlighted as stick model. c, Cleavage of ISG15-AMC was measured and normalized to DMSO control. IC 50 value of GRL-0617 in relation to SCoV2-PLpro activity is presented. Data are mean \pm s.d. $n=3$ independent experiments. catalytic site, in which a protease $\mathrm{S} 2$ site binds the distal ubiquitin in the K48-linked chain, or the N-terminal ubiquitin-like fold in ISG15. Whereas SCoV-PLpro Leu76 mediates a hydrophobic interaction with Ile44 on ubiquitin, the corresponding residue on SCoV2-PLpro is Thr75 (Fig. 2c). To mimic the hydrophobic interaction observed in SCoV-PLpro, we generated two variants of SCoV2-PLpro (T75A and T75L). The T75L mutant, but not T75A, resulted in a $\mathrm{K} 48-\mathrm{Ub}_{2}-\mathrm{AMC}$ cleavage (Fig. $2 \mathrm{~d}$ ). This indicates that the presence and size of the hydrophobic residue at this site are critical determinants for ubiquitin binding. We also compared papain-like proteases from other coronaviruses, including the common human coronaviruses OC43, 229E and NL63 (Extended Data Fig. 3). The $\mathrm{S} 2$ binding site in papain-like proteases is poorly conserved across coronaviruses and exhibits variable hydrophobicity at the position corresponding to Thr75 of SCoV2-PLpro, which might influence substrate specificity.

Next, we examined whether other residues in SCoV2-PLpro contribute to its enhanced affinity for ISG15. SCoV2-PLpro Val66 faces the hydrophobic patch (Ala2, Thr20 and Met23) on the N-terminal ubiquitin fold domain of ISG15 (Fig. 2e). Both PLpro enzymes share Phe (SCoV2-PLpro Phe69 and SCoV-PLpro Phe70) as the core residue mediating hydrophobic interactions with either ubiquitin or ISG15. Mutating Phe69 (F69A) or Val66 (V66A) on SCoV2-PLpro decreased its enzymatic activity and showed slower reaction with ISG15-Prg compared to the wild type (Fig. 2f).

The interaction between SCoV2-PLpro and K48-Ub 2 and mouse ISG15 was also examined using molecular dynamics simulations (Extended Data Fig. 2d, e). Multi-microsecond molecular dynamics simulations confirmed that SCoV2-PLpro interacts more tightly with ISG15 compared with $\mathrm{K} 48-\mathrm{Ub}_{2}$ (reconfirming $K_{\mathrm{d}}$ values measured in Fig. 1e). In three independent runs of $3.2 \mu \mathrm{s}$, ISG15 remained bound as in the SCoV2-PLpro-ISG15 X-ray structure. By contrast, the distal ubiquitin of $\mathrm{K} 48-\mathrm{Ub}_{2}$ separated from SCoV2-PLpro in four out of six runs on a microsecond time scale. We identified L75T to be the differentiator between $\mathrm{K} 48-\mathrm{Ub}_{2}$ and SCoV-PLpro, as it weakens the hydrophobic cluster within the binding interface. We observed that water transiently enters between K48-Ub 2 Ile 44 and SCoV2-PLpro Thr75 before dissociation. Indeed, in simulations of the SCoV-PLpro double mutant (S67V/L76T) with $\mathrm{K} 48-\mathrm{Ub}_{2}$, a similar water-mediated dissociation mechanism was observed (Extended Data Fig. 2f, g). Together, these results suggest that the $\mathrm{S} 2$ region determines substrate specificity and that SCoV2-PLpro shows a relative preference towards ISG15.

\section{GRL-0617 is an inhibitor of SCoV2-PLpro}

Given the urgency to identify novel therapeutic strategies against COVID-19, we tested the effect of GRL-0617, a non-covalent inhibitor of SCoV-PLpro ${ }^{18}$, on SCoV2-PLpro (Fig. 3a). GRL-0617 was developed as an inhibitor of SCoV-PLpro and does not inhibit other host proteases $^{18,19}$. On the basis of the binding mode of GRL-0617 and other naphthalene-based inhibitors to SCoV-PLpro ${ }^{18-21}$, we postulated that the conserved Tyr268 of SCoV2-PLpro could also bind GRL-0617 and block the entry of the ISG15 C terminus towards the catalytic cleft of the protease (Fig. 3b, Extended Data Fig. 4a-c). Indeed, the half maximal inhibitory concentration $\left(\mathrm{IC}_{50}\right.$ ) of GRL-0617 for SCoV2-PLpro was similar to the one for SCoV-PLpro (Fig. 3c, Extended Data Fig. 4d, e).GRL-0617 is ineffective against MERS-PLpro ${ }^{22}$; we hypothesized that this could be due to the presence of Thr instead of Tyr at this conserved position (Tyr268 in SCoV2-PLpro) (Extended Data Fig. 3a). Accordingly, the mutation of Tyr268 to either Thr (Y269T) or Gly (Y268G) in SCoV2-PLpro strongly reduced the inhibitory effect of GRL-0617 (Fig. 3c, Extended Data Fig. 4d, e), indicating the critical role of Tyr268 in this process. Molecular dynamics simulations of GRL-0617 with SCoV-PLpro and SCoV2-PLpro further confirmed a common binding mode between GRL-0617 and Tyr268 (Tyr269 in SCoV-PLpro) (Extended Data Fig. 4b,c).

To assess the potential therapeutic value of GRL-0617 against COVID-19, we tested the effect of GRL-0617 on the deISGylase or deubiquitinase activities of SCoV2-PLpro on host proteins. GRL-0617 effectively blocked SCoV2-PLpro activity, leading to increased levels of ISGylated proteins in lysates of IFN- $\alpha$-treated cells (Extended Data Fig. 4f). GRL-0617 also blocked the deubiquitination activity of SCoV-PLpro (Extended Data Fig. 4f). Of note, the effects of GRL-0617 on

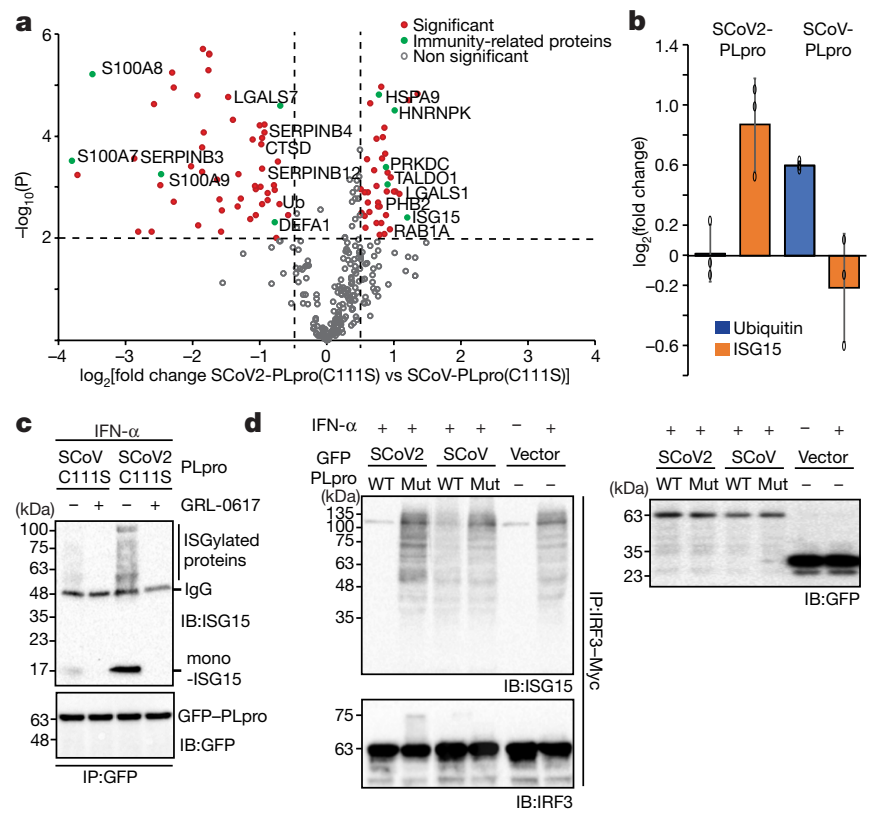

Fig. 4 | Effect on PLpros on IFN and NF-KB pathways. a, Interactome analysis comparing SCoV2-PLpro(C111S) and SCoV-PLpro(C111S). Statistically significant and immunity-related proteins are highlighted. $\mathbf{b}, \log _{2}$ (fold change) of ubiquitin and ISG15 proteins enriched by SCoV2-PLpro or SCoV-PLpro immunoprecipitates versus empty vector. Data are mean \pm s.d. $(n=3$, independent experiments). c, ISGylated proteins were enriched from A549 cells treated with IFN- $\alpha\left(200 \mathrm{U} \mathrm{ml}^{-1}\right)$ by immunoprcipitation of the indicated C111S mutant PLPro.d, ISGylation level of Myc-IRF3 in A549 cells expressing the indicated GFP-PLpro. Experiments in $\mathbf{c}, \mathbf{d}$, were repeated three times independently with similar results. 
a

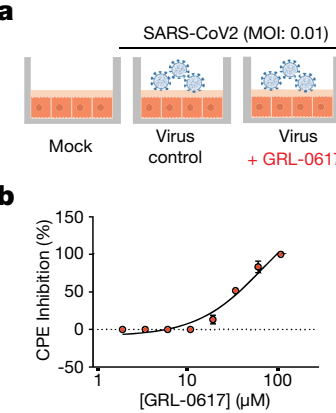

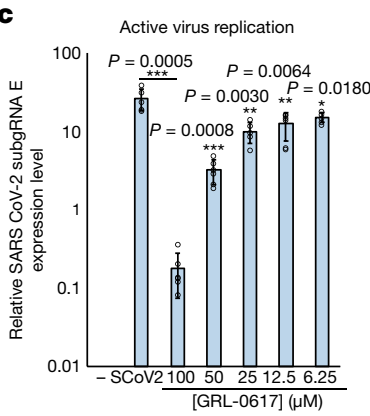

d Virus release in medium

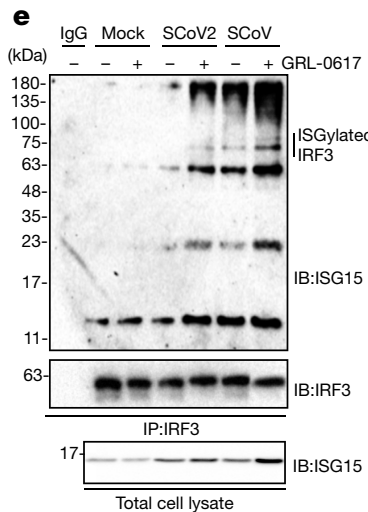

$\mathbf{f}$

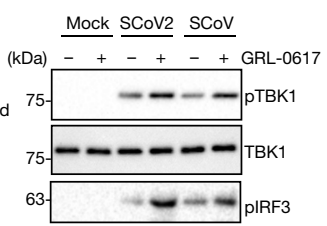

$\mathbf{g}$
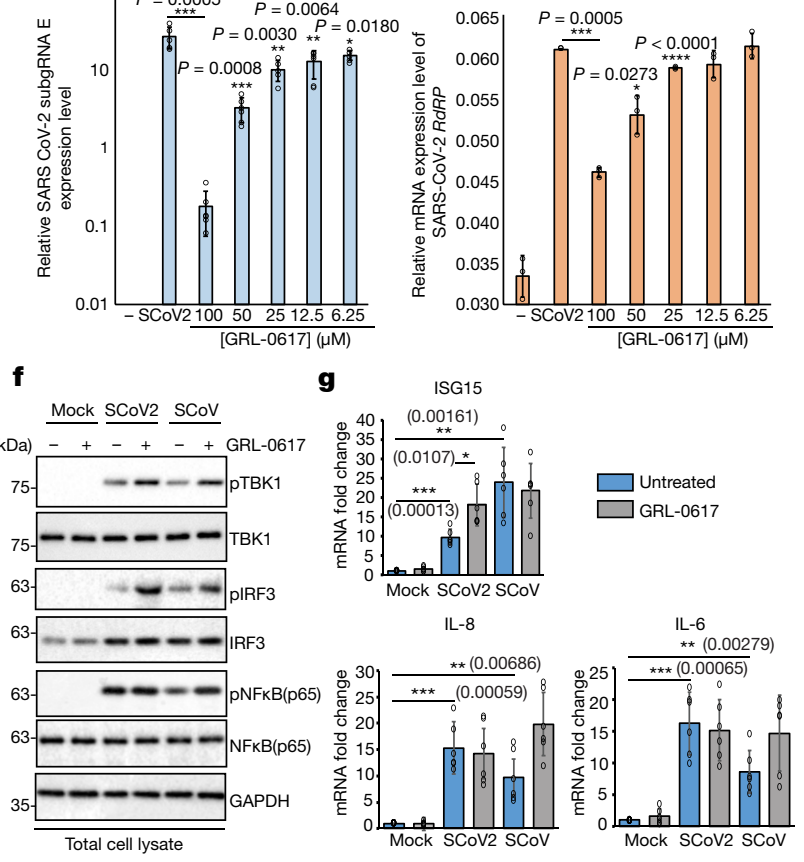

Fig. 5 | Inhibitory effects of GRL-0617 on SARS-CoV2. a, Schematic representation of the SARS-CoV-2 (strain FFM1) growth inhibition test with GRL-0617. MOI, multiplicity of infection. b, CPE inhibition rate of GRL-0617 on $\mathrm{CaCo}-2$ cells infected with SARS-CoV2. c, Intracellular active virus replication was analysed by measuring SARS-CoV-2 subgenomic RNA (subgRNA E) level and normalized to the cellular $A C T B$ gene. d, Release of viral particles in culture medium was analysed by PCR targeting the open reading frame of the RNA-dependent RNA polymerase $(R d R P)$ gene of SARS-CoV-2.e,f, The effect of GRL-0617 on the type IIFN pathway. CaCo-2 cells were infected with SARS-CoV-2 or SARS-CoV with or without GRL-0617 $(50 \mu \mathrm{M})$. pTBK1, phosphorylated TBK1;
pIRF3, phosphorylated IRF3; pNF-кB p65, phosphorylated pNF-кB p65. e, Endogenous IRF3 was immunoprecipitated and analysed by immunoblotting. f, Phosphorylation of TBK1 was analysed by immunoblotting. $\mathbf{g}$, Relative mRNA levels of indicated genes from infected cells with or without GRL-0617 $(25 \mu \mathrm{M})$ treatment were analysed and normalized to $18 \mathrm{~S}$ RNA. $P$ values in parentheses. Data in $\mathbf{c}, \mathbf{d}, \mathbf{g}$, are mean \pm s.d.; $n=3$ independent experiments. ${ }^{*} P<0.05,{ }^{* *} P<0.01,{ }^{* * *} P<0.001,{ }^{* * * *} P<0.0001$; two-tailed paired $t$-test. Experiments in $\mathbf{e}, \mathbf{f}$, were repeated three times independently with similar results. the reaction between Prg probes with SCoV2-PLpro were more prominent with $\mathrm{ISG}_{\mathrm{C}} 5_{\mathrm{C} \text {-erm }}-\mathrm{Prg}$ than $\mathrm{ISG}_{\mathrm{FL}}-$ Prg or ubiquitin versus $\mathrm{K} 48-\mathrm{Ub}_{2}$ to SCoV-PLpro (Extended Data Fig. $4 \mathrm{~g}$, h), which is consistent with the structural data indicating that the ISG15 $\mathrm{N}$-terminal ubiquitin-fold domain potentiates the interaction with SCoV2-PLpro. These results showed that GRL-0617 inhibits both SCoV2-PLpro and SCoV-PLpro.

\section{PLpro regulates IFN and NF-KB pathways}

To understand the differences in the pathophysiological roles of SCoV2-PLpro and SCoV-PLpro, and to expand our knowledge of the SARS-CoV-2 protein interaction map ${ }^{23}$, we analysed the cellular interactome of both proteins. ISG15 was significantly enriched in complexes with a catalytically inactive version of SCoV2-PLpro (C111S), whereas a SCoV-PLpro mutant (C111S) predominantly associated with ubiquitin (Fig. 4a, b). In mammalian cells treated with type IIFNs (IFN- $\alpha$ ), unconjugated ISG15 and ISG15-positive smears (probably representing ISGylated substrates) on western blots were more pronounced in immunoprecipitates of GFP-SCoV2-PLpro(C111S) than those of GFP-SCoV-PLpro(C111S) (Fig. 4c). GRL-0617 treatment blocked this association (Fig. 4c). Moreover, these closely related PLpro enzymes associate with distinct and specific sets of host proteins (Fig. 4a). For SCoV2-PLpro, these interactions include PRKDC (associated with induction by type I interferons ${ }^{24}$ ), heterogenous nuclear ribonucleoprotein K (HNRNPK; involved in host RNA splicing, a process essential for SARS-CoV-2 replication in cells ${ }^{25}$ ) and galectin1, which can induce viral fusion with target cells during HIV infection ${ }^{26}$ (Fig. 4a). By contrast
SCoV-PLpro strongly associates with several serine protease inhibitors (serpins), including serpin B3, which has been proposed to inhibit papain proteases ${ }^{27,28}$. Co-expression of serpin B3 with PLpro enzymes partially restored NF-KB signalling in cells expressing SCoV-PLpro, but had no effect on SCoV2-PLpro regulation of the IFN pathway (Extended Data Fig. 5a, b).

Consistently, expression of SCoV2-PLpro and SCoV-PLpro in mammalian cells decreased ISGylation of cellular proteins following IFN- $\alpha$ stimulation (Extended Data Fig. 5c), including ISGylation of interferon regulatory factor 3 (IRF3), a critical component in the type 1 interferon pathway ${ }^{29}$. Both SCoV2-PLpro and SCoV-PLpro reduced IRF3 ISGylation, with SCoV2-PLpro having a more potent effect (Fig. 4d). Decreases in phosphorylation of TBK1 and IRF3, and nuclear translocation of IRF3 were detected upon expression of SCoV-PLpro or SCoV2-PLpro (Extended Data Fig. 5d, e). SCoV2-PLpro(C111S) showed stronger dominant negative effects on IRF3 phosphorylation compared with SCoV-PLpro(C111S) (Extended Data Fig. 5d, e). TBK1 phosphorylation also activates the NF-KB pathway, causing upregulation of inflammatory signalling ${ }^{30}$. Although expression of SCoV-PLpro had less effect on IRF3 ISGylation (Fig. 4d), it strongly attenuated degradation of IKB- $\alpha$ (Extended Data Fig. 5f, g). SCoV-PLpro also caused a severe reduction in nuclear translocation of p65 in cells treated with TNF (Extended Data Fig. 5h).

Sensing of viral nucleic acids is mimicked by poly(l:C) treatment, which induces IFN- $\beta$ expression ${ }^{31}$. Expression of SCoV2-PLpro more effectively decreased the activation of the IFNB1 promoter compared with SCoV-PLpro following poly(I:C) treatment. This inhibitory effect 
of both PLpro enzymes was neutralized by GRL-0617 treatment (Extended Data Fig. 6a, c). By contrast, expression of SCoV-PLpro predominantly blocked TNF-induced NF-KB p65 expression, also in a GRL-0617-dependent manner (Extended Data Fig. 6b, d). Together, we show how two closely related coronaviruses (SARS and SARS-CoV-2) differentially counteract the host immune system using their PLpro enzymes.

\section{Role of PLpro in viral spread and IFN responses}

GRL-0617 has been shown to inhibit viral replication of SARS-CoV ${ }^{18}$. Thus, to determine whether inhibiting SCoV2-PLpro can also block SARS-CoV-2 replication, we infected CaCo-2 cells with SARS-CoV-2 and treated them with GRL-0617 (Fig. 5a). The effect of GRL-0617 was measured by inhibition of cytopathogenic effect (CPE). We observed a gradual dose-dependent inhibition of SARS-CoV-2-induced CPE in the presence of GRL-0617, with $100 \mu \mathrm{M}$ GRL-0617 almost completely inhibiting CPE (Fig. 5b). In addition, GRL-0617 treatment reduced active viral replication (SARS-CoV-2 subgenomic RNA4-encoding E gene), as measured by genetic monitoring of the intracellular production of viral RNA (Fig. 5c). Consequently, a decrease in the release of viral particles from infected cells into the supernatant was also observed upon GRL-0617 treatment (Fig. 5d, Extended Data Fig. 7a). This suggests that inhibition of SCoV2-PLpro by GRL-0617 impedes viral replication, thereby attenuating the ongoing viral RNA synthesis.

Having demonstrated a role for expression of SCoV2-PLpro and SCoV-PLpro in attenuating host antiviral IFN pathways, we anticipated that inhibition by GRL-0617 would reverse this process. Indeed, GRL-0617 treatment of SARS-CoV-2-infected cells led to a marked increase in IRF3 ISGylation (Fig. 5e), which has previously been shown to regulate antiviral immune response ${ }^{32}$. Moreover, phosphorylation of IRF3 and TBK1, markers for IFN pathway activation, and p65 phosphorylation, used to monitor NF-KB pathway activation, were increased in SARS-CoV-2-infected cells upon GRL-0617 treatment (Fig. 5f). Notably, GRL-0617 treatment significantly rescued the expression of IFN-responsive genes (ISG15, OAS1, PKR (also known as EIF2AK2)) and $M X 1$ ) in SARS-CoV-2-infected cells (Fig. 5g, Extended Data Fig. 7b). These findings provide evidence that inhibition of SCoV2-PLpro, in addition to blocking viral RNA synthesis, can also increase antiviral signalling via TBK1 and IRF3 (Extended Data Fig. 7c). Although experiments conducted with GRL-0617 provide evidence supporting the therapeutic value of pharmacologically targeting SCoV2-Plpro in patients, the low potency of GRL-0617 suggests that additional studies are needed to develop more potent and selective PLpro inhibitors.

Finally, we tested changes in $\mathrm{CaCo}-2$ cells upon infection with SARS-CoV and SARS-CoV-2. GRL-0617 treatment of infected cells showed an overall similar pattern in biochemical and transcriptional parameters of the type I IFN and NF-KB pathways (Fig. 5e-g). However, we found that GRL-0617 was consistently more effective in restoring ISGylation and phosphorylation level of IRF3 and expression of IFN-responsive genes upon infection with SARS-CoV-2 compared with SARS-CoV (Fig. 5e-g). By contrast, transcription levels of the proinflammatory cytokines IL- 6 and IL- 8 appeared similar between SARS-CoV and SARS-CoV-2 in this epithelial cell culture model (Fig. 5g). Consistent with these observations, a recent study has shown that SARS-CoV-2 infection in animal models and in human patients with COVID-19 is correlated with low IFN type I and type III responses ${ }^{33}$. Although preferential deISGylation activity of SCoV2-PLpro may contribute to decreased type I IFN signalling, more detailed studies are needed to understand the key regulatory factors contributing to innate and adaptive immunity that control the distinct pathologic outcomes of SARS-CoV and SARS-CoV-2 infections ${ }^{34}$.

In summary, this study provides mechanistic understanding of the functions of SCoV2-PLpro during SARS-CoV-2 infection and establishes SCoV2-PLpro as a promising target for therapeutic intervention against COVID-19. Recent reports of newly identified inhibitors of SCoV2-PLpro ${ }^{35-37}$ could lead to the rapid development of novel anti-COVID-19 therapeutics with dual effects-blocking SARS-CoV-2 spread and promoting antiviral immunity in the host. Furthermore, the main protease of SARS-CoV-2 has been in focus as a potential drug target against COVID-19 and several novel inhibitors have already been described ${ }^{38-40}$. Combining drugs targeting essential SARS-CoV-2 proteases (PLpro and/or main protease) with drugs targeting SARS-CoV-2 RNA-dependent polymerase may offer successful therapeutic options in future ${ }^{41}$.

\section{Online content}

Any methods, additional references, Nature Research reporting summaries, source data, extended data, supplementary information, acknowledgements, peer review information; details of author contributions and competing interests; and statements of data and code availability are available at https://doi.org/10.1038/s41586-020-2601-5

1. Harcourt, B. H. et al. Identification of severe acute respiratory syndrome coronavirus replicase products and characterization of papain-like protease activity. J. Virol. 78, 13600-13612 (2004)

2. Lim, K. P., Ng, L. F. P. \& Liu, D. X. Identification of a novel cleavage activity of the first papain-like proteinase domain encoded by open reading frame 1 a of the coronavirus Avian infectious bronchitis virus and characterization of the cleavage products. J. Virol. 74, 1674-1685 (2000).

3. Frieman, M., Ratia, K., Johnston, R. E., Mesecar, A. D. \& Baric, R. S. Severe acute respiratory syndrome coronavirus papain-like protease ubiquitin-like domain and catalytic domain regulate antagonism of IRF3 and NF-KB signaling. J. Virol. 83, 6689-6705 (2009).

4. Devaraj, S. G. et al. Regulation of IRF-3-dependent innate immunity by the papain-like protease domain of the severe acute respiratory syndrome coronavirus. J. Biol. Chem. 282, 32208-32221 (2007).

5. Bailey-Elkin, B. A. et al. Crystal structure of the Middle East respiratory syndrome coronavirus (MERS-CoV) papain-like protease bound to ubiquitin facilitates targeted disruption of deubiquitinating activity to demonstrate its role in innate immune suppression. J. Biol. Chem. 289, 34667-34682 (2014).

6. Huang, C. et al. Clinical features of patients infected with 2019 novel coronavirus in Wuhan, China. Lancet 395, 497-506 (2020).

7. Lu, R. et al. Genomic characterisation and epidemiology of 2019 novel coronavirus: implications for virus origins and receptor binding. Lancet 395, 565-574 (2020).

8. Zhou, P. et al. A pneumonia outbreak associated with a new coronavirus of probable bat origin. Nature 579, 270-273 (2020).

9. Sommer, S., Weikart, N. D., Linne, U. \& Mootz, H. D. Covalent inhibition of SUMO and ubiquitin-specific cysteine proteases by an in situ thiol-alkyne addition. Bioorg. Med. Chem. 21, 2511-2517 (2013).

10. Ekkebus, R. et al. On terminal alkynes that can react with active-site cysteine nucleophiles in proteases. J. Am. Chem. Soc. 135, 2867-2870 (2013).

11. Flierman, D. et al. Non-hydrolyzable diubiquitin probes reveal linkage-specific reactivity of deubiquitylating enzymes mediated by S2 pockets. Cell Chem. Biol. 23, 472-482 (2016).

12. Basters, A. et al. Structural basis of the specificity of USP18 toward ISG15. Nat. Struct. Mol. Biol. 24, 270-278 (2017).

13. Geurink, P. P. et al. Profiling DUBs and Ubl-specific proteases with activity-based probes. Methods Enzymol. 618, 357-387 (2019).

14. Freitas, B. T. et al. Characterization and noncovalent inhibition of the deubiquitinase and deISGylase activity of SARS-CoV-2 papain-like protease. ACS Infect. Dis. 6, 2009-2109 (2020).

15. Basters, A. et al. Molecular characterization of ubiquitin-specific protease 18 reveals substrate specificity for interferon-stimulated gene 15. FEBS J. 281, 1918-1928 (2014).

16. Clasman, J. R., Everett, R. K., Srinivasan, K. \& Mesecar, A. D. Decoupling delSGylating and deubiquitinating activities of the MERS virus papain-like protease. Antiviral Res. 174, 104661 (2020)

17. Daczkowski, C. M. et al. Structural insights into the interaction of coronavirus papain-like proteases and interferon-stimulated gene product 15 from different species. J. Mol. Biol. 429, 1661-1683 (2017).

18. Ratia, K. et al. A noncovalent class of papain-like protease/deubiquitinase inhibitors blocks SARS virus replication. Proc. Natl Acad. Sci. USA 105, 16119-16124 (2008).

19. Báez-Santos, Y. M. et al. X-ray structural and biological evaluation of a series of potent and highly selective inhibitors of human coronavirus papain-like proteases. J. Med. Chem. 57, 2393-2412 (2014).

20. Ghosh, A. K. et al. Severe acute respiratory syndrome coronavirus papain-like novel protease inhibitors: design, synthesis, protein-ligand X-ray structure and biological evaluation. J. Med. Chem. 53, 4968-4979 (2010).

21. Ghosh, A. K. et al. Structure-based design, synthesis, and biological evaluation of a series of novel and reversible inhibitors for the severe acute respiratory syndrome-coronavirus papain-like protease. J. Med. Chem. 52, 5228-5240 (2009).

22. Kilianski, A. \& Baker, S. C. Cell-based antiviral screening against coronaviruses: developing virus-specific and broad-spectrum inhibitors. Antiviral Res. 101, 105-112 (2014). 


\section{Article}

23. Gordon, D. E. et al. A SARS-CoV-2 protein interaction map reveals targets for drug repurposing. Nature 583, 459-468 (2020)

24. Ferguson, B. J., Mansur, D. S., Peters, N. E., Ren, H. \& Smith, G. L. DNA-PK is a DNA sensor for IRF-3-dependent innate immunity. eLife 1, e00047 (2012)

25. Bojkova, D. et al. Proteomics of SARS-CoV-2-infected host cells reveals therapy targets. Nature 583, 469-472 (2020)

26. Ouellet, M. et al. Galectin-1 acts as a soluble host factor that promotes HIV-1 infectivity through stabilization of virus attachment to host cells. J. Immunol. 174, 4120-4126 (2005).

27. Schick, C. et al. Cross-class inhibition of the cysteine proteinases cathepsins $K, L$, and S by the serpin squamous cell carcinoma antigen 1: a kinetic analysis. Biochemistry $\mathbf{3 7}$, 5258-5266 (1998)

28. Takeda, A., Yamamoto, T., Nakamura, Y., Takahashi, T. \& Hibino, T. Squamous cell carcinoma antigen is a potent inhibitor of cysteine proteinase cathepsin L. FEBS Lett. 359, 78-80 (1995)

29. Stetson, D. B. \& Medzhitov, R. Type I interferons in host defense. Immunity 25, 373-381 (2006).

30. Liu, T., Zhang, L., Joo, D. \& Sun, S.-C. NF-KB signaling in inflammation. Signal Transduct. Target. Ther. 2, 17023 (2017)

31. Sheikh, F., Dickensheets, H., Gamero, A. M., Vogel, S. N. \& Donnelly, R. P. An essential role for IFN- $\beta$ in the induction of IFN-stimulated gene expression by LPS in macrophages. $J$. Leukoc. Biol. 96, 591-600 (2014).

32. Shi, H.-X. et al. Positive regulation of interferon regulatory factor 3 activation by Herc 5 via ISG15 modification. Mol. Cell. Biol. 30, 2424-2436 (2010).

33. Blanco-Melo, D. et al. Imbalanced host response to SARS-CoV-2 drives development of COVID-19. Cell 181, 1036-1045 (2020).
34. Niemeyer, D. et al. The papain-like protease determines a virulence trait that varies among members of the SARS-coronavirus species. PLoS Pathog. 14, e1007296 (2018).

35. Anson, B. J. et al. Broad-spectrum inhibition of coronavirus main and papain-like 2 proteases by HCV drugs. Preprint at https://doi.org/10.21203/rs.3.rs-26344/v1 (2020).

36. Shanker, A. K., Bhanu, D., Alluri, A. \& Gupta, S. Whole-genome sequence analysis and homology modelling of the main protease and non-structural protein 3 of SARS-CoV-2 reveal an aza-peptide and a lead inhibitor with possible antiviral properties. New J. Chem. 44, 9202-9212 (2020).

37. Rut, W. et al. Activity profiling and structures of inhibitor-bound SARS-CoV-2-PLpro protease provides a framework for anti-COVID-19 drug design. Preprint at bioRxiv https:// doi.org/10.1101/2020.04.29.068890 (2020).

38. Zhang, L. et al. Crystal structure of SARS-CoV-2 main protease provides a basis for design of improved a-ketoamide inhibitors. Science 368, 409-412 (2020).

39. Jin, Z. et al. Structure of Mpro from COVID-19 virus and discovery of its inhibitors. Nature 582, 289-293 (2020)

40. Dai, W. et al. Structure-based design of antiviral drug candidates targeting the SARS-CoV-2 main protease. Science 368, 1331-1335 (2020).

41. Lo, H. S. et al. Simeprevir suppresses SARS-CoV-2 replication and synergizes with remdesivir. Prepint at bioRxiv https://doi.org/10.1101/2020.05.26.116020 (2020)

Publisher's note Springer Nature remains neutral with regard to jurisdictional claims in published maps and institutional affiliations.

(c) The Author(s), under exclusive licence to Springer Nature Limited 2020 


\section{Methods}

No statistical methods were used to predetermine sample size. The experiments were not randomized. The investigators were not blinded to allocation during experiments and outcome assessment.

\section{Plasmids construction}

The papain-like protease domain sequence was obtained from the SARS-CoV-2 complete genome (NCBI genome databank, Severe acute respiratory syndrome coronavirus 2 isolate Wuhan-Hu-1, complete genome; NC_045512). Protein sequence for CoV2 PLpro Ubl domain (amino acids, 746-1060) of Nsp3 protein from SARS-CoV-2 (Nsp3; YP_009725299.1) was codon optimized, synthesized and cloned into pET28b with Ncol and Xhol to have C-terminal His-tag (Genescript). Protein sequences of the PLpro-Ubl domain of SARS and MERS (PDB ID: $3 \mathrm{MJ} 5$ and 5W8U, respectively $\mathrm{y}^{20,42}$ ) were also codon optimized, synthesized and cloned into $\mathrm{pET} 28 \mathrm{~b}$ with $\mathrm{Ncol}$ and Xhol to add C-terminal His tags (Genescript). Mutants were generated by PCR and verified by sequencing. For mammalian expression, PLpros were cloned into pEGFP-C1 (clontech). To produce the vector pACE-ISG15, a synthetic cDNA was used for murine ISG15 (residues 1-155) with an added $\mathrm{N}$-terminal $\mathrm{His}_{6}$ tag and the recognition site for the HRV-3C protease (Mr. Gene).

\section{Protein purification}

BL21(DE3) Escherichia coli competent cells (NEB) were transformed with plasmids and grown in LB medium to an OD600 of 0.6-0.8 at $37^{\circ} \mathrm{C}$. Protein production was induced by addition of $0.5 \mathrm{mM}$ isopropyl-D-thiogalactopyranoside (IPTG) and $1 \mathrm{mM}$ zinc chloride $\left(\mathrm{ZnCl}_{2}\right)$. The cells were further grown overnight at $18^{\circ} \mathrm{C}$ and collected. The cell pellet was resuspended in lysis buffer $(50 \mathrm{mM}$ Tris- $\mathrm{HCl}, 150 \mathrm{mM}$ $\mathrm{NaCl}, 10 \mathrm{mM}$ Imidazole, $2 \mathrm{mM} \mathrm{DTT}, \mathrm{pH} 8.5$ ) and lysed by sonication and centrifuged at $13,000 \mathrm{rpm}$ to clarify the supernatant. The supernatant was incubated $2 \mathrm{~h}$ with TALON beads (Takara) pre-equilibrated with lysis buffer and non-specific proteins were cleared with washing. Proteins were eluted with elution buffer $(50 \mathrm{mM}$ Tris- $\mathrm{HCl}, 150 \mathrm{mM} \mathrm{NaCl}$, $250 \mathrm{mM}$ imidazole, $2 \mathrm{mM}$ DTT, pH 8.5). Eluted proteins were buffer exchanged to storage buffer $(20 \mathrm{mM}$ Tris- $\mathrm{HCl}, 100 \mathrm{mM} \mathrm{NaCl}, 2 \mathrm{mM}$ DTT, pH 8.5) and stored for biochemical analysis. For crystallization of SCoV2-PLpro(C111S), the cell pellet was resuspended in lysis buffer (50 mM Tris- $\mathrm{HCl}, 150 \mathrm{mM} \mathrm{NaCl}, 10 \mathrm{mM}$ imidazole, $1 \mathrm{mM} \mathrm{TCEP}, \mathrm{pH} 7.4$ ) and lysed by sonication and centrifuged at $13,000 \mathrm{rpm}$ to clarify the supernatant. The supernatant was incubated $2 \mathrm{~h}$ with TALON beads (Takara) pre-equilibrated with lysis buffer and non-specific proteins were cleared with washing. Proteins were eluted with elution buffer (50 mM Tris- $\mathrm{HCl}, 150 \mathrm{mM} \mathrm{NaCl}, 250 \mathrm{mM}$ imidazole, $1 \mathrm{mM} \mathrm{TCEP}, \mathrm{pH} 7.4$ ) and further purified on size-exclusion column (Superdex 7516/60, GE Healthcare) pre-equilibrated with $20 \mathrm{mM}$ Tris- $\mathrm{HCl}, 100 \mathrm{mM} \mathrm{NaCl}, 1 \mathrm{mM}$ TCEP, $\mathrm{pH7.4}$. Proteins were concentrated to $20 \mathrm{mg} \mathrm{ml}^{-1}$ and stored for crystallization. For the expression of mouse ISG15, BL21(DE3) E. coli competent cells (NEB) were transformed with pACE-ISG15. A single bacterial colony was picked and transferred in $5 \mathrm{ml} \mathrm{DYT} \mathrm{medium} \mathrm{with}$ $0.2 \%(\mathrm{w} / \mathrm{v})$ glucose and $100 \mu \mathrm{g} \mathrm{ml}^{-1}$ ampicillin and grown overnight at $37^{\circ} \mathrm{C}$. The preculture was centrifuged for $3 \mathrm{~min}$ at $3,000 \mathrm{~g}$ centrifuged and resuspended in $5 \mathrm{ml}$ of fresh medium. Two litres of DYT medium was mixed with $5 \mathrm{ml}$ of the pre-culture and grown at $37^{\circ} \mathrm{C}$ until it reached an OD600 of 0.6. Protein expression was induced by adding IPTG (final concentration $1 \mathrm{mM}$ ). The cells were grown for $20 \mathrm{~h}$ at $28^{\circ} \mathrm{C}$ and collected by centrifugation $\left(10 \mathrm{~min}, 5,000 \mathrm{~g}, 4^{\circ} \mathrm{C}\right)$. Five grams of $E$. coli pellet (ISG15 or ISG15(C76S)) were thawed on ice and resuspended in $30 \mathrm{ml}$ of buffer A-ISG15 (50 mM Na $2 \mathrm{HPO}_{4}, 500 \mathrm{mM} \mathrm{NaCl} \mathrm{pH} \mathrm{7.0,1}$ protease inhibitor tablet (Roche)). The cells were disrupted using a French press and the lysate was centrifuged for $1 \mathrm{~h} 40,000 \mathrm{~g}$ and $4{ }^{\circ} \mathrm{C}$. All cleaning steps were carried out with an ÄkTA chromatography system (GE Healthcare) at $4{ }^{\circ} \mathrm{C}$. The supernatant was applied to a $15 \mathrm{ml}$
Ni-FF Sepharose column (GE Healthcare). The column was filled with 4 column volumes of $50 \mathrm{mM} \mathrm{Na}_{2} \mathrm{HPO}_{4}, 500 \mathrm{mM} \mathrm{NaCl}, 15 \mathrm{mM}$ imidazole pH 7.0, washed and the protein was eluted with a linear imidazole gradient over 20 column volumes and final imidazole concentration of $500 \mathrm{mM}$ (buffer B-ISG15). About $30 \mathrm{mg}$ of the eluted protein was treated with $1 \mathrm{mg} \mathrm{His}{ }_{6}-\mathrm{HRV}-3 \mathrm{C}$ and dialysed against buffer A-ISG15 at $16^{\circ} \mathrm{C}$ for $16 \mathrm{~h}$. The protein was then applied to the same column containing the protein, concentrated to about $6 \mathrm{mg} \mathrm{ml}^{-1}$ and further purified with a size-exclusion column (Superdex 7516/60, GE Healthcare) pre-equilibrated with $20 \mathrm{mM}$ Tris- $\mathrm{HCl}, 100 \mathrm{mM} \mathrm{NaCl}, 1 \mathrm{mM} \mathrm{TCEP}, \mathrm{pH} 7.4$.

\section{Ubiquitin, NEDD8, SUMO and ISG15 activity-based probe assay}

PLpro proteins were diluted ( $2 \mu \mathrm{M}$ final concentration) with activation buffer (25 mM Tris- $\mathrm{HCl} \mathrm{pH} \mathrm{7.5,150} \mathrm{mM} \mathrm{NaCl,10} \mathrm{mMDTT)} \mathrm{and} \mathrm{incubated}$ for $10 \mathrm{~min}$ at $25^{\circ} \mathrm{C}$. and the activity-based probes were diluted $\left(0.2 \mathrm{mg} \mathrm{ml}^{-1}\right.$ final concentration) in dilution buffer ( $50 \mathrm{mM}$ Tris- $\mathrm{HCl} 7.5,150 \mathrm{mM} \mathrm{NaCl})$. The reaction mixture was prepared by mixing equal volume of activated PLpro proteins $(2 \mu \mathrm{M})$ and activity-based probes $\left(0.2 \mathrm{mg} \mathrm{ml}^{-1}\right)$. Reactions were conducted at indicated temperature (on ice $\left(0^{\circ} \mathrm{C}\right)$ or $\left.37^{\circ} \mathrm{C}\right)$ and samples were taken at the indicated time points and the reactions were quenched by the addition of SDS sample buffer. Samples were further analysed by SDS-PAGE and stained with a silver staining kit (Thermo Fisher).

\section{AMC probe-based kinetic assay}

For determination of enzyme kinetics $\left(k_{\text {cat }}\right.$ and $\left.K_{\mathrm{m}}\right)$, ubiquitin-AMC or ISG15-AMC was used as substrate of PLpro or mouse USP18 and the release of $\mathrm{AMC}$ was measured by increase of fluorescence (excitation/ emission, 360/487 $\mathrm{nm}$ ) on a 384-well microplate reader (PHERAstar FSX, BMG Labtech). Fvie microlitres of solution containing different concentration of $\mathrm{K} 48-\mathrm{Ub}_{2}-\mathrm{AMC}(76-0 \mu \mathrm{M})$ or ISG15-AMC $(40-0 \mu \mathrm{M})$ were aliquoted into 384 well plate and reaction was initiated by addition of $5 \mu \mathrm{l}$ of PLpro or mouse USP18 (20 nM) to the well. Initial velocities of AMC release were normalized to a standard curve and the velocity versus substrate concentration plot were further analysed by Michaelis-Menten enzymatic kinetics, using the $k_{\text {cat }}$ function with fixed value of total enzyme concentration as provided above. The experiment was repeated at least three times.

\section{Bio-layer interferometry}

Binding kinetics were determined with the OctetRed system (Fortebio). Either SCoV2-PLpro(C111S) or SCoV-PLpro(C111S) at $1 \mu \mathrm{M}$ were loaded onto an Ni-NTA biosensor and equilibrated with binding buffer for the baseline. To examine the association rate, equilibrated sensors were transferred into solutions containing various concentration of $\mathrm{K} 48-\mathrm{Ub}_{2}$ $(90-0 \mu \mathrm{M})$, human ISG15 $(3-0 \mu \mathrm{M})$ or mouse ISG15 $(90-0 \mu \mathrm{M})$. Dissociation of PLpro was initiated by placing the sensor into reaction buffer. Values of association rate constant $\left(k_{\text {on }}\right)$, dissociation rate constant $\left(k_{\text {off }}\right)$ and dissociation constant $\left(K_{\mathrm{d}}\right)$ values were calculated by Octet Data analysis software (ForteBio).

\section{Crystallization}

Equal amounts of SCoV2-PLpro(C111S) and full-length murine ISG15 were mixed, giving a final concentration of $250 \mu \mathrm{M}$. Protein mixtures were screened with sitting-drop matrix screens in a 96-well plate with $100 \mathrm{nl}$ of protein and $100 \mathrm{nl}$ of precipitant solution at $293 \mathrm{~K}$. Initial crystals appeared from solution containing 20\% PEG 3350, $200 \mathrm{mM}$ potassium thiocyanate with $125 \mu \mathrm{M}$ protein. To optimize the crystallization condition, we diluted the protein to vary the concentration, and the diffraction-quality crystals were grown in optimized solution containing 18\% PEG 3350, 100 mM bis-tris propane $\mathrm{pH} 6.5,200 \mathrm{mM}$ potassium thiocyanate with $100 \mu \mathrm{M}$ protein.

\section{Data collection, processing and structure determination}

Crystals were cryo-protected using mother liquor solution supplemented with $25 \%$ (v/v) ethylene glycerol. Diffraction data were collected 
on single frozen crystal in a nitrogen stream at $100 \mathrm{~K}$ at $1.00001 \AA$ in the X06SA beamline at the Swiss Light Source, Villigen. Initial data sets were processed using $\mathrm{XDS}^{43}$, and phases were determined by Phaser molecular replacement in ccp4 module with SCoV2-PLpro and mouse ISG15 as the template model ${ }^{44}$; PDB IDs: 6 W9C and 5TLA). Structure refinement and manual model building were performed with Coot and Phenix.Refine ${ }^{45,46}$ (Extended Data Table 1). There were $93.26 \%$ and $6.74 \%$ of the residues in the favoured and allowed regions of the Ramachandran plot respectively, and no residues were found in disallowed regions.

\section{Cell lysates, deubiquitination and deISGylation assay}

HeLa or A549 cells were treated with IFN- $\alpha\left(200 \mathrm{U} \mathrm{ml}^{-1}\right)$ for $48 \mathrm{~h}$ to induce ISGylation. Cells were lysed with lysis buffer ( $50 \mathrm{mM}$ Tris- $\mathrm{HCl}(\mathrm{pH} 8.0)$, $150 \mathrm{mM} \mathrm{NaCl}, 1 \%(\mathrm{v} / \mathrm{v}) \mathrm{NP}-40)$ and concentration was measured with the BCA assay (Thermo Fisher). Ten micrograms of lysates were incubated with $100 \mathrm{nM}$ of PLpro for indicated time points at $37^{\circ} \mathrm{C}$ and analysed by immunoblotting with indicated antibodies. To test the inhibitory effect of GRL-0617, $40 \mu \mathrm{M}$ of GRL-0617 was included during the reaction. Images were obtained using Image lab software (Bio-Rad).

\section{Deneddylation and IKB $\alpha$ deubiquitination assay}

All proteins described are of human origin. CUL1-RBX1, SKP1- $\beta-T R C P 2$, UBE2M, UBE2D3, NEDD8, UB, APPBP1-UBA3 and UBA1 were purified as previously described ${ }^{47}$. Neddylated CUL1-RBX1 was generated as previously described ${ }^{47}$. The reaction for generating hyperneddylated CUL1-RBX1 was driven at $\mathrm{pH} 8.8$ at $37^{\circ} \mathrm{C}$ for $30 \mathrm{~min}$ and purified by size exclusion chromatography. The USP 2 catalytic core was purified with nickel affinity chromatography, liberated of the His tag by overnight thrombin cleavage, followed by ion exchange and size-exclusion chromatography. Den1 was purified by GST affinity chromatography, liberated of the GST tag by overnight TEV cleavage, followed by ion exchange and size-exclusion chromatography. The Cop9 signallosome (CSN) was purified as previously described ${ }^{48}$. Deneddylation assays were performed with $1 \mu \mathrm{M}$ hyperneddylated CUL1-RBX1, and $5 \mu \mathrm{M}$ protease (SCoV-PLpro, SCoV2-PLpro, DEN1 and USP2) or $20 \mathrm{nM} \mathrm{CSN.}$ The reaction was performed at $37^{\circ} \mathrm{C}$ in $25 \mathrm{mM}$ Tris $100 \mathrm{mM} \mathrm{NaCl}, 5 \mathrm{mM}$ DTT pH 8.5, and in the case of CSN, with and additional $10 \mathrm{mM} \mathrm{MgCl}_{2}$. Samples were taken at each indicated time point and quenched with $2 \times$ SDS-PAGE sample buffer. Gels were stained by Coomassie blue and scanned on an Amersham imager 600. IkB $\alpha$ deubiquitylation assays were performed by first generating a ubiquitylated IKB $\alpha$, with $200 \mathrm{nM}$ UBA1, $1 \mu$ MUBE2D3, $20 \mu \mathrm{M} U B, 500 \mathrm{nM}$ neddylated CRL1- $\beta$-TRCP, and $5 \mu \mathrm{M}$ fluorescently labelled IkB $\alpha$ at $37^{\circ} \mathrm{C}$ in $50 \mathrm{mM}$ Tris, $50 \mathrm{mM} \mathrm{NaCl}$, $10 \mathrm{mM} \mathrm{MgCl} 2,5 \mathrm{mM}$ DTT pH 7.5 for $30 \mathrm{~min}$. Reaction was quenched by adding $80 \mathrm{mM}$ EDTA for $5 \mathrm{~min}$. The deubiquitylation reaction was started by mixing $3 \mu \mathrm{M}$ of protease (SCoV-PLpro, SCoV2-PLpro or USP2) with the ubiquitylation reaction, and samples were taken at each time point and quenched with $2 \times$ SDS-PAGE sample buffer. Gels were scanned on an Amersham Typhoon (GE) detecting the fluorescently labelled IKB $\alpha$.

\section{Molecular dynamics simulations}

SCoV-PLpro (wild type and double mutant) and SCoV2-PLpro with K48-Ub $\mathbf{H}_{\mathbf{2}}$. The coordinates of SCoV-PLpro with bound K48-Ub ${ }_{2}$ were taken from PDB ID: $5 E 6 \mathrm{~J}^{49}$. For the double mutant setup, the mutations S67V and L76T were introduced using MODELLER ${ }^{50}$. For SCoV2-PLpro with bound $\mathrm{K} 48-\mathrm{Ub}_{2}$, we set up two models. We combined the substrate coordinates taken from PDB ID: 5E6J with (1) the X-ray crystal structure of the unbound form (PDB ID: 6W9C, re-refined by T. Croll (University of Cambridge, UK) (https://drive.google.com/drive/folders/1JB o50CdkBU7K1pFThuqrzhQ-NcsIAWyG) and (2) with the X-ray crystal structure of the SCoV2-PLpro-mouse ISG15 complex (PDB ID: 6YVA) after PLpro alignment using $\mathrm{PyMol}^{51}$. In all di-ubiquitin systems, the triazole linker was replaced with Lys using MODELLER. To mimic the linker, a harmonic-distance restraint potential was applied between the backbone carbonyl carbon atoms of Lys 48 and Gly 75 with a target distance of $9.5 \AA$ and a force constant of $502,080 \mathrm{~kJ} \mathrm{~mol}^{-1} \mathrm{~nm}^{-2}$. The covalent propargylamide linker was removed.

SCoV-PLpro and SCoV2-PLpro in complex with inhibitor GRL-0617. The coordinates of the SCoV-PLpro-GRL-0617 complex were taken from PDB ID: $3 \mathrm{E}^{18}{ }^{18}$. The oxidized Cys112 was changed to the reduced form (SH) using MODELLER. The simulation model of the SCoV2-PLproGRL-0617 complex was built according to the X-ray structure of the unbound form of SCoV2-PLpro (PDB ID: 6W9C, re-refined by T. Croll). The coordinates of the compound GRL-0617 were modelled according to PDB ID: 3E9S after PLpro alignment using PyMol. The blocking loop 2 (BL2 loop, GNYQCGH) capping the GRL-0617 binding site was remodelled according to the SCoV-PLproX-ray crystal structure of the complex (PDB ID: 3E9S) ${ }^{18}$ using MODELLER. The GRL-0617 ligand was parameterized with the general amber force field $(\mathrm{GAFF})^{52}$.

SCoV2-PLpro with mouse ISG15. The X-ray crystal structure of the SCoV2-PLpro-mouse ISG15 complex (PDB ID: 6YVA) served as starting point. Missing residues of SCoV2-PLpro and one $\mathrm{Zn}$ ion were modelled according to the X-ray crystal structure (PDB ID: 6W9C, re-refined by T. Croll).

Missing side chains in all setups were modelled using MODELLER. All crystallographic water molecules and ions were retained, except a nickel ion in PDB ID:5E6J. According to $\mathrm{p} K_{\mathrm{a}}$ calculations using Prop $K_{\mathrm{a}}$ and additional visual inspections, in all setups His17 of SCoV2-PLpro (His18 of SCoV-PLpro) and His272 of SCoV2-PLpro (His273 of SCoV-PLpro) were charged. We cannot exclude that the protonation state of the catalytic His272 of SCoV2-PLpro (His273 of SCoV-PLpro) is in equilibrium between charged and neutral forms. All other residues were simulated in their physiological protonation state. The proteins were solvated in TIP4P-D water ${ }^{53}$ with $150 \mathrm{mM} \mathrm{NaCl}$. Molecular dynamics simulations were carried out using Gromacs $2018^{54}$ and the AMBER99SB*-ILDN-q force field ${ }^{55-58}$. Each system was energy minimized, followed by five equilibration steps, in which we gradually weakened the position restraints on heavy atoms, first in an NVT ensemble $(0.25 \mathrm{~ns})$ and then in an NPT ensemble $(4 \times 0.5 \mathrm{~ns})$ using a Berendsen thermostat and barostat ${ }^{59}$. Production simulations were run at a temperature of $310 \mathrm{~K}$ and a pressure of 1 bar in an NPT ensemble using a Nosé-Hoover thermostat ${ }^{60,61}$ and a Parrinello-Rahman barostat ${ }^{62}$. We set up three independent runs of the SCoV2-PLpro systems with bound substrates, starting from different MODELLER results for the apo-like model of SCoV2-PLpro:K48-Ub ${ }_{2}$ and for the SCoV2-PLpro-mouse ISG15 complex. For simulations with bound substrates and with bound inhibitor, we monitored the root-mean-square deviation (r.m.s.d.) of each backbone substrate (distal ubiquitin in $\mathrm{K} 48-\mathrm{Ub}_{2}$ and $\mathrm{N}$-terminal domain of mouse ISG15) and of GRL-0617 (heavy atoms) to the respective equilibrated structure after alignment on the helix backbone of PLpro (without the flexible UBL domain). From simulations of SCoV-PLpro-K48-Ub ${ }_{2}$, we extracted the minimum heavy-atom distance between F70 of SARS and 144 of ubiquitin.

\section{Inhibitor $\mathrm{IC}_{50}$ determination}

For IC ${ }_{50}$ value for inhibitors, ubiquitin-AMC or ISG15-AMC was used as substrate of PLpro and the release of AMC was measured by increase of fluorescence (excitation/emission, 360/487 nm) on a 384-well microplate reader (PHERAstar FSX, BMG Labtech). Five microlitres of solution containing different concentrations of GRL-0617 $(200-0 \mu \mathrm{M})$ and 10 $\mu \mathrm{M}$ of ubiquitin-AMC or ISG15-AMC were aliquoted into 384 well plate and reaction was initiated by addition of $5 \mu \mathrm{l}$ of PLpro $(30 \mathrm{nM})$ to the well. Initial velocities of AMC release were normalized against DMSO control. The $\mathrm{IC}_{50}$ value was calculated by the dose-response-inhibition function in Graphpad Prism with [inhibitor] vs normalized response equation. The experiment was repeated three times. 


\section{Mass-spectrometry}

For interactome analysis, A549 cells were transfected with wild-type or mutant (C111S) SCoV-PLpro or SCoV2-PLpro, and for comparison between SARS-CoV and SARS-CoV-2, PLpro(C111S) versions of both proteins were transfected. Cells were stimulated with IFN- $\alpha(200 \mathrm{U}$ $\mathrm{ml}^{-1}$ ) for $36 \mathrm{~h}$ to mimic an infection scenario. Cells were lysed in ice cold lysis buffer ( $50 \mathrm{mM}$ Tris- $\mathrm{Cl}, \mathrm{pH} 7.5 ; 150 \mathrm{mM} \mathrm{NaCl} ; 1 \%$ Triton X-100) and equal amounts of lysates were incubated with GFP nanotrap beads in IP buffer (Lysis buffer without detergent). After incubation, immunoprecipitates were washed three times with wash buffer (50 $\mathrm{mM}$ Tris- $\mathrm{HCl}, \mathrm{pH} 7.5 ; 400 \mathrm{mM} \mathrm{NaCl} ; 0.5 \mathrm{mM}$ EDTA) and two times with IP buffer. Then, beads were incubated with $25 \mu$ l of $50 \mathrm{mM}$ Tris- $\mathrm{HCl}$ ( $\mathrm{pH}$ 8.5) containing $4 \mathrm{M}$ urea, $1 \mathrm{mM} \mathrm{TCEP}, 4 \mathrm{mM}$ chloroacetamide for $1 \mathrm{~h}$ in the dark at $37^{\circ} \mathrm{C}$. Afterwards, samples were diluted with $50 \mathrm{mM}$ Tris- $\mathrm{HCl} \mathrm{pH} 8.5$ to a final urea concentration $<2 \mathrm{M}$ and digested with 0.5 $\mu \mathrm{g}$ trypsin (Promega) at $37^{\circ} \mathrm{C}$ overnight. Digests were acidified using trifluoroacetic acid to a pH of 2-3 and peptides were desalted using C18-stage tips ${ }^{63}$. Peptides were labelled with tandem mass tag (TMT) reagents (Thermo fisher) as described previously ${ }^{64}$. In brief, peptides were resuspended in TMT labelling buffer (0.2 M EPPS pH 8.2, 20\% acetonitrile) and were mixed with TMT reagents in a 2:1 TMT: peptide ratio. Reaction was performed for one hour at room temperature and subsequently quenched by addition of hydroxylamine to a final concentration of $0.5 \%$ at room temperature for $15 \mathrm{~min}$. Samples were pooled in equimolar ratio, acidified and again cleaned-up using C18-stage tips. After drying, peptides were resuspended in $0.1 \%$ formic acid for liquid chromatography-mass spectrometry. All mass spectrometry data was acquired in centroid mode on an Orbitrap Fusion Lumos mass spectrometer hyphenated to an easy-nLC 1200 nano HPLC system with a nanoFlex ion source (ThermoFisher Scientific). A spray voltage of $2.6 \mathrm{kV}$ was applied with the transfer tube heated to $300^{\circ} \mathrm{C}$ and funnel RF set to $30 \%$. Internal mass calibration was enabled (lock mass $445.12003 \mathrm{~m} / \mathrm{z}$ ). Peptides were separated on a self-made $32 \mathrm{~cm}$ long, $75 \mu \mathrm{m}$ internal diameter fused-silica column, packed in house with 1.9 $\mu \mathrm{m} \mathrm{C18}$ particles (ReproSil-Pur, Dr. Maisch) and heated to $50{ }^{\circ} \mathrm{C}$ using an integrated column oven (Sonation). HPLC solvents consisted of $0.1 \%$ formic acid in water (buffer $\mathrm{A}$ ) and $0.1 \%$ formic acid, $80 \%$ acetonitrile in water (buffer B). Peptides were eluted by a nonlinear gradient from 7 to $40 \%$ buffer B over 90 min followed by a step-wise increase to $95 \%$ buffer B in 6 min which was held for another $9 \mathrm{~min}$. Full scan mass spectra $(350-1400 \mathrm{~m} / z)$ were acquired with a resolution of 120,000 at $\mathrm{m} / z 200$, maximum injection time of $100 \mathrm{~ms}$ and AGC target value of $4 \times 10^{5}$. The 20 most intense precursors per full scan with a charge state between 2 and 5 were selected for fragmentation ('Top 20'), isolated with a quadrupole isolation window of $0.7 \mathrm{Th}$ and fragmented via higher-energy collisional dissociation applying a normalized collision energy of $38 \%$. MS2 scans were performed in the Orbitrap using a resolution of 50,000 at $\mathrm{m} / z 200$, maximum injection time of $86 \mathrm{~ms}$ and automatic gain control target value of $1 \times 10^{5}$. Repeated sequencing of already acquired precursors was limited by setting a dynamic exclusion of $60 \mathrm{~s}$ and $7 \mathrm{ppm}$ and advanced peak determination was deactivated. Raw mass spectrometry data were analysed with Proteome Discoverer (v.2.4, ThermoFisher Scientific) using Sequest HT as a search engine and performing re-calibration of precursor masses by the Spectrum RC-node. Fragment spectra were searched against the human reference proteome ('one sequence per gene', 20,531 sequences, version March 2020) and protein sequences for SARS (15 sequences, version March 2020) and CoV2 (14 sequences, version February 2020) downloaded from Uniprot in March 2020, as well as common contaminants as included in 'contaminants.fasta' provided with the MaxQuant software. Static modifications were TMT at the peptide $\mathrm{N}$ terminus and lysines as well as carbamidomethyl at cysteine residues, dynamic modifications were set as oxidation of methionine and acetylation at the protein $\mathrm{N}$-terminus. Matched spectra were filtered with Percolator, applying a false discovery rate of $1 \%$ on peptide spectrum match and protein level. Reporter intensities were normalized to the total protein intensities in Proteome Discoverer, assuming equal sample loading and additionally by median normalization using the NormalyzerDE package $^{65}$. Statistically significant changes between samples were determined in Perseus (v.1.6.6.0) and significant candidates were chosen having $p$-value $\leq 0.01$ and $\log _{2}$ (fold change) value minimum of \pm 0.5 (ref. ${ }^{66}$ ).

\section{Cell culture}

Human CaCo-2 cells were obtained from the Deutsche Sammlung vonMikroorganismen und Zellkulturen. Cells were grown at $37^{\circ} \mathrm{C}$ in Minimal Essential Medium (MEM) supplemented with $10 \%$ fetal bovine serum (FBS) and containing $100 \mathrm{IU} \mathrm{ml}^{-1}$ penicillin and $100 \mu \mathrm{g} \mathrm{ml}^{-1}$ streptomycin. A549 and HeLa cells were obtained from ATCC (ATCC CCL-185 and ATCC CCL-2, respectively). All cell lines used tested negative for mycoplasma.

\section{Antibodies}

We used the following antibodies and dilutions for this study: ubiquitin (catalogue (cat.) no. 3936S, Cell Signaling Technology; 1:20:00), ISG15 (cat. no. HPA004627, Sigma Aldrich/Merck; 1:1,000), GAPDH (cat. no. 2118, Cell Signaling Technology; 1:2,000), GFP trap beads (cat no. gta-100, ChromoTek), GFP (cat. no. sc-9996, Santa Cruz Biotechnology; 1:2,000), IRF3 (cat. no. 4302, Cell Signaling Technology; 1:2,000), phospho-IRF3(Ser396) (cat. no. 4947, Cell Signaling Technology; 1:1,000), IкB $\alpha$ (cat. no. 4812, Cell Signaling Technology; 1:2,000), phospho-ІкB $\alpha($ Ser32/36) (cat. no. 9246, Cell Signaling Technology; 1:1,000), TBK1 (cat. no.3013, Cell Signaling Technology;1:2,000), pTBK1 (cat. no. 3300-1 Epitomics; 1:1,000), NF-KB p65 (cat. no. 8008, Santa Cruz Biotechnology; 1:2,000), lamin B1 (cat. no. sc-373918, Santa Cruz Biotechnology; 1:2,000).

\section{Virus preparation}

SARS-CoV-2 strain FFM1 (accession no. MT358638) ${ }^{67}$ was isolated from travellers returning from Wuhan (China) to Frankfurt (Germany) using CaCo- 2 cells. SARS-CoV-2 FFM1 stocks used in the experiments had undergone one passage on CaCo-2 cells, as described previously ${ }^{25}$.Virus titres were determined as $\mathrm{TCID}_{50}$ per $\mathrm{ml}$ in confluent cells in 96-well microtitre plates.

\section{Antiviral and cytotoxicity assays}

Confluent layers of CaCo-2 cells in 96-well plates were infected with SARS-CoV-2 FFM1 at a MOI of 0.01. Virus was added simultaneously with GRL-0617 and incubated in MEM supplemented with 1\% FBS with different drug dilutions. CPE was assessed visually $48 \mathrm{~h}$ after infection. To assess effects of GRL-0617 on CaCo- 2 cell viability, confluent cell layers were treated with different drug concentration. Cell viability was determined by MTT assay, modified after Mosman ${ }^{68}$, as previously described $^{69}$. Data for each condition were collected for at least three biological replicates.

\section{Luciferase activity assay}

To analyse the induction of IFN- $\beta$ induced genes, a luciferase reporter assay was used in A549 cells. In brief, an expression construct containing the luciferase ORF and the IFN- $\beta$ promoter (IFN- $\beta$-luciferase) was co-transfected with either a GFP control plasmid or the designated PLpro plasmid. For all transfections, 100 ng of luciferase plasmid, $400 \mathrm{ng}$ of PLpro or GFP vector was used in each well of a 12-well plate All transfections were performed in triplicate and the average of three experiments is shown in figures. Twenty-four hours after transfection, cells were treated with $500 \mathrm{ng}$ poly(I:C) for $18 \mathrm{~h}$ or $50 \mathrm{ng} \mathrm{ml}^{-1}$ of TNF for $30 \mathrm{~min}$. Luciferase expression was measured using the Luciferase Reporter Assay System (Promega). Fold change was calculated by taking vector treated with poly $(\mathrm{I}: \mathrm{C})$ or TNF as 1 . 


\section{Immunofluorescence and confocal imaging}

HeLa cells expressing GFP-tagged PLpro was treated with TNF $\left(50 \mathrm{ng} \mathrm{ml}^{-1}\right)$ for $45 \mathrm{~min}$. Cells were fixed with paraformaldehyde, blocked in $5 \%$ serum and immunostained overnight at $4{ }^{\circ} \mathrm{C}$ with antibody against p65. Confocal imaging was performed using the Zeiss LSM780 microscope system. An Ar ion laser (for excitation of GFP at $488 \mathrm{~nm}$ ), a He-Ne laser (for excitation of Alexa Fluor $546 \mathrm{~nm}$ ) were used with a $63 \times 1.4 \mathrm{NA}$ oil-immersion objective. Images were analysed in FIJI to determine colocalization between DAPI and immunostained p65. Results are indicative of 50 cells taken from 3 independent experiments; error bars indicate standard deviation.

\section{Nuclear fractionation}

A549 cells from a confluent $60-\mathrm{mm}$ dish were transiently transfected with GFP-tagged PLPro followed by treatment with IFN- $\alpha\left(200 \mathrm{ml}^{-1}\right.$, $36 \mathrm{~h}$ ). Cells were lysed in hypotonic buffer (10 mM HEPES ( $\mathrm{pH} 7.4)$, $2 \mathrm{mM} \mathrm{MgCl}_{2}, 25 \mathrm{mM} \mathrm{KCl}, 1 \mathrm{mM} \mathrm{DTT}, 1 \mathrm{mM} \mathrm{PMSF}$, and protease inhibitor cocktail), kept on ice for $30 \mathrm{~min}$ followed by syringe lysis, and 2 M sucrose solution was added dropwise, followed by centrifugation at $1,000 \mathrm{~g}$ for $15 \mathrm{~min}$. The supernatant was saved as the cytosolic fraction. The pellet was washed twice in wash buffer $(10 \mathrm{mM}$ HEPES ( $\mathrm{pH} 7.4$ ), $2 \mathrm{mM} \mathrm{MgCl}_{2}, 25 \mathrm{mM} \mathrm{KCl}, 250 \mathrm{mM}$ sucrose, $1 \mathrm{mM} \mathrm{DTT}, 1 \mathrm{mM}$ PMSF, and protease inhibitor cocktail) and saved as the nuclear fraction.

\section{Quantification of viral and cellular RNA}

SARS-CoV-2 RNA from cell culture supernatant samples was isolated using ACL buffer and the QIAamp 96 Virus kit (Qiagen) according to the manufacturer's instructions. RNA was subjected to OneStep quantitative $\mathrm{PCR}$ with reverse transcription (RT-qPCR) analysis using the LightCycler Multiplex RNA Virus Master kit (Roche). Intracellular RNA was isolated using RLT buffer and the RNeasy 96 HT Kit according to the manufacturer's instructions. PCR was performed on a CFX96 Real-Time System, C1000 Touch Thermal Cycler. Primers and probe were adapted from the $\mathrm{WHO}$ protocol ${ }^{70}$ targeting the open reading frame of RNA-dependent RNA polymerase $(R d R P)$ of both SARS-CoV-2: RdRP_SARSr-F2 (GTGARATGGTCATGTGTGGCGG) and RdRP_SARSr-R1 (CARATGTTAAASACACTATTAGCATA) primers were used at a final concentration of $0.4 \mu \mathrm{M}$ and RdRP_SARSr_P2 probe (6-Fam CAGGTGGAACCTCATCAGGAGATGC BBQ1) was used at $0.2 \mu \mathrm{M}$. Primers for ACTB (fwd: CATCGAGCACGGCATCGTCA; rev: TAGCACAGCCT GGATAGCAAC) $^{71}$,ISG15 (fwd:GAGAGGCAGCGAACTCATCT; rev:AGGGAC ACCTGGAATTCGTT) ${ }^{72}$ IL6 (fwd: GCAGAAAAAGGCAAAGAATC; rev: CTACATTTGCCGAAGAGC), IL 8 (fwd: GTTTTTGAAGAGGGCTGAG; rev: TTTGCTTGAAGTTTCACTGG) and 18S rRNA (fwd: AGAAACGGC TACCACATCCA ; rev: CACCAGACTTGCCCTCCA) were used for SYBR green-based detection of cellular genes in a final concentration of $0.4 \mu \mathrm{M}$ per reaction. For each condition, three biological replicates were used. Mean and s.d. were calculated for each group. For interferon-responsive genes, the following primers were used. $M X 1$ (fwd:TTTTCAAGAAGGAGGCCAGCAA; rev:TCAGGAACTTCCGCTTGT CG), OAS1 (fwd:TGGCCTTCTATGCCCTCTATCC; rev: TCCCATCAGGTGC ACAGAAGA) and $P K R$ (fwd:GGAACTTTGCGATACATGAGCC;rev:CGTCCC GTAGGTCAGTGAAAAA). SARS-CoV-2 subgenomic RNA4 encoding E gene, which is processed during discontinuous transcription in productively infected cells $\mathrm{s}^{73}$, was quantified using primer pairs ( $\mathrm{fwd}$ : AACGTACCTGTCTCTTCCGA; rev: CCAACCAACTTTCGATCTCTTGT) spanning a junction of the SARS-CoV-2 subgenomic RNAs and used as a measure of viral activity.

\section{Reporting summary}

Further information on research design is available in the Nature Research Reporting Summary linked to this paper.

\section{Data availability}

The atomic coordinates of PLpro-mouse ISG15 have been deposited in the PDB with accession code 6YVA. The mass spectrometry data have been deposited to the ProteomeXchange Consortium ${ }^{74}$ via the PRIDE partner repository ${ }^{75}$ with the data set identifier PXD018983. The papain-like protease domain sequence was obtained from the SARS-CoV-2 complete genome (NCBI nucleotide, severe acute respiratory syndrome coronavirus 2 isolate Wuhan-Hu-1, complete genome; NC_045512). Protein sequence for SCoV2-PLpro Ubl domain (amino acids, 746-1060) of Nsp3 protein from SARS-CoV-2 (Nsp3; YP_009725299.1). Full gel images are shown in Supplementary Fig. 1. Any other relevant data are available from the corresponding authors upon reasonable request. Source data are provided with this paper.

42. Daczkowski, C. M., Goodwin, O. Y., Dzimianski, J. V., Farhat, J. J. \& Pegan, S. D. Structurally guided removal of DelSGylase biochemical activity from papain-like protease originating from Middle East respiratory syndrome coronavirus. J. Virol. 91, e01067-17 (2017).

43. Kabsch, W. XDS. Acta Crystallogr. D 66, 125-132 (2010).

44. McCoy, A. J. et al. Phaser crystallographic software. J. Appl. Cryst. 40, 658-674 (2007).

45. Afonine, P. V. et al. Towards automated crystallographic structure refinement with phenix. refine. Acta Crystallogr. D 68, 352-367 (2012).

46. Emsley, P., Lohkamp, B., Scott, W. G. \& Cowtan, K. Features and development of Coot. Acta Crystallogr. D 66, 486-501 (2010).

47. Baek, K. et al. NEDD8 nucleates a multivalent cullin-RING-UBE2D ubiquitin ligation assembly. Nature 578, 461-466 (2020).

48. Enchev, R. I. et al. Structural basis for a reciprocal regulation between SCF and CSN. Cell Rep. 2, 616-627 (2012).

49. Békés, M. et al. Recognition of Lys48-linked di-ubiquitin and deubiquitinating activities of the SARS coronavirus papain-like protease. Mol. Cell 62, 572-585 (2016)

50. Šali, A. \& Blundell, T. L. Comparative protein modelling by satisfaction of spatial restraints. J. Mol. Biol. 234, 779-815 (1993)

51. Schrödinger, L. The PyMol Molecular Graphics System, version 1.8. (2015)

52. Wang, J., Wolf, R. M., Caldwell, J. W., Kollman, P. A. \& Case, D. A. Development and testing of a general amber force field. J. Comput. Chem. 25, 1157-1174 (2004).

53. Piana, S., Donchev, A. G., Robustelli, P. \& Shaw, D. E. Water dispersion interactions strongly influence simulated structural properties of disordered protein states. J. Phys. Chem. B 119, 5113-5123 (2015).

54. Abraham, M. J. et al. GROMACS: High performance molecular simulations through multi-level parallelism from laptops to supercomputers. SoftwareX 1-2, 19-25 (2015).

55. Hornak, V. et al. Comparison of multiple Amber force fields and development of improved protein backbone parameters. Proteins 65, 712-725 (2006)

56. Best, R. B., de Sancho, D. \& Mittal, J. Residue-specific a-helix propensities from molecular simulation. Biophys. J. 102, 1462-1467 (2012).

57. Best, R. B. \& Hummer, G. Optimized molecular dynamics force fields applied to the helix-coil transition of polypeptides. J. Phys. Chem. B 113, 9004-9015 (2009).

58. Lindorff-Larsen, K. et al. Improved side-chain torsion potentials for the Amber ff99SB protein force field. Proteins 78, 1950-1958 (2010).

59. Berendsen, H. J. C., Postma, J. P. M., van Gunsteren, W. F., DiNola, A. \& Haak, J. R. Molecular dynamics with coupling to an external bath. J. Chem. Phys. 81, 3684-3690 (1984).

60. Evans, D. J. \& Holian, B. L. The Nose-Hoover thermostat. J. Chem. Phys. 83, 4069-4074 (1985)

61. Nosé, S. A unified formulation of the constant temperature molecular dynamics methods. J. Chem. Phys. 81, 511-519 (1984)

62. Parrinello, M. \& Rahman, A. Polymorphic transitions in single crystals: a new molecular dynamics method. J. Appl. Phys. 52, 7182-7190 (1981).

63. Rappsilber, J., Ishihama, Y. \& Mann, M. Stop and go extraction tips for matrix-assisted laser desorption/ionization, nanoelectrospray, and LC/MS sample pretreatment in proteomics. Anal. Chem. 75, 663-670 (2003).

64. Klann, K., Tascher, G. \& Münch, C. Functional translatome proteomics reveal converging and dose-dependent regulation by mTORC1 and elF2a. Mol. Cell 77, 913-925 (2020).

65. Willforss, J., Chawade, A. \& Levander, F. NormalyzerDE: online tool for improved normalization of omics expression data and high-sensitivity differential expression analysis. J. Proteome Res. 18, 732-740 (2019).

66. Tyanova, S. et al. The Perseus computational platform for comprehensive analysis of (prote)omics data. Nat. Methods 13, 731-740 (2016).

67. Toptan, T. et al. Optimized qRT-PCR approach for the detection of intra- and extracellular SARS-CoV-2 RNAs. Int. J. Mol. Sci. 21, 4396 (2020).

68. Mosmann, T. Rapid colorimetric assay for cellular growth and survival: application to proliferation and cytotoxicity assays. J. Immunol. Methods 65, 55-63 (1983).

69. Onafuye, H. et al. Doxorubicin-loaded human serum albumin nanoparticles overcome transporter-mediated drug resistance in drug-adapted cancer cells. Beilstein $\mathrm{J}$. Nanotechnol. 10, 1707-1715 (2019)

70. Corman, V. M. et al. Detection of 2019 novel coronavirus (2019-nCoV) by real-time RT-PCR. Euro Surveill. 25, 2000045 (2020).

71. Zhang, X., Ding, L. \& Sandford, A. J. Selection of reference genes for gene expression studies in human neutrophils by real-time PCR. BMC Mol. Biol. 6, 4 (2005).

72. Moll, H. P., Maier, T., Zommer, A., Lavoie, T. \& Brostjan, C. The differential activity of interferon-a subtypes is consistent among distinct target genes and cell types. Cytokine 53, 52-59 (2011)

73. Kim, D. et al. The architecture of SARS-CoV-2 transcriptome. Cell 181, 914-921 (2020).

74. Vizcaíno, J. A. et al. ProteomeXchange provides globally coordinated proteomics data submission and dissemination. Nat. Biotechnol. 32, 223-226 (2014). 
75. Vizcaíno, J. A. et al. 2016 update of the PRIDE database and its related tools. Nucleic Acids Res. 44 (D1), D447-D456 (2016).

Acknowledgements We thank A. Gubas, C. Joazeiro, D. Hoeller and K. Koch for critical comments on the manuscript. We also thank Swiss Light Source (SLS) for providing special beam time for this project during the peak of the COVID-19 pandemic in Switzerland and W. Meitian and $O$. Vincent for providing on-site support during the data collection. We thank the Quantitative Proteomics Unit (IBCII, Goethe University Frankfurt) for support and expertise in sample preparation, LC-MS instrumentation and data analysis. This work was supported by the DFG-funded Collaborative Research Centre on Selective Autophagy (SFB 1177), by the Max Planck Society, by NWO (H.O. and G.J.v.d.H.v.N.) by the European Research Council (ERC) under the European Union's Horizon 2020 research and innovation programme (grant agreement no. 789016) to B.A.S., LYSFOR2625 (DFG) to A.B. and (grant agreement no. 742720) to I.D., by the grants from Else Kroener Fresenius Stiftung, Dr. Rolf M. Schwiete Stiftung, and by internal IBC2 funds to I.D.

Author contributions D.S. and I.D. conceived the project. D.S. contributed protein purification biochemical and biophysical activity assay and structure determination. R.M. performed cell biology experiments. D.G. contributed protein purification. D.B. contributed virus infection experiments, M.W. and A.W. performed RT-qPCR measurements, K.B. performed the deneddylation assay. A.B. and G.T. designed and performed mass spectrometry experiments and analysed data. L.S. and A.R.M. performed molecular dynamics simulations. K.R.

contributed to RT-qPCR materials and critical advice. P.P.G. and G.J.v.d.H.v.N. synthesized Ub(l) probes and reagents in the laboratory of H.O. S.M. and K.-P.K. provided Ubl probes and reagents. B.A.S., G.H., J.C., S.C. and I.D. supervised the project. D.S. and I.D. analysed the data and wrote the manuscript with input from all co-authors.

Competing interests The authors declare no competing interests.

Additional information

Supplementary information is available for this paper at https://doi.org/10.1038/s41586-020 2601-5.

Correspondence and requests for materials should be addressed to I.D.

Peer review information Nature thanks Rolf Hilgenfeld, Ingrid Wertz and the other, anonymous, reviewer(s) for their contribution to the peer review of this work.

Reprints and permissions information is available at http://www.nature.com/reprints. 
PLpro Sequence similiarity (identity), (\%)

\begin{tabular}{|c|c|c|c|}
\hline & SARS & CoV2 & MERS \\
\hline SARS & 100 & $\mathbf{8 8 . 6 ( 8 2 . 9 )}$ & $51.4(34.4)$ \\
\hline CoV2 & & 100 & $51.1(32.9)$ \\
\hline MERS & & & 100 \\
\hline
\end{tabular}

b
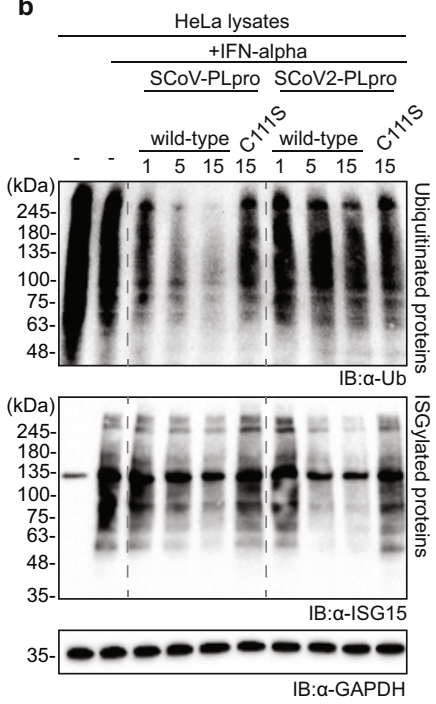

f

ISG15-Prg

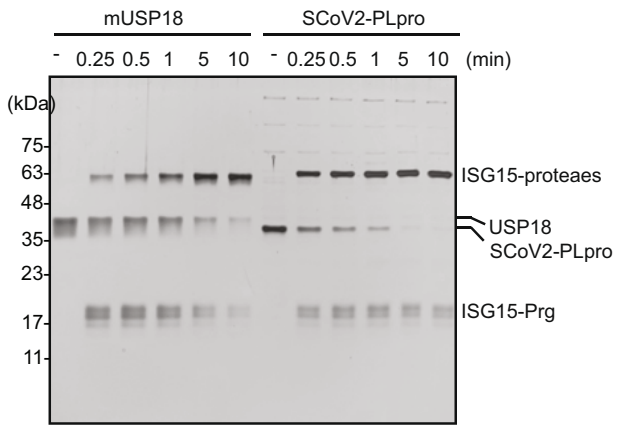

i

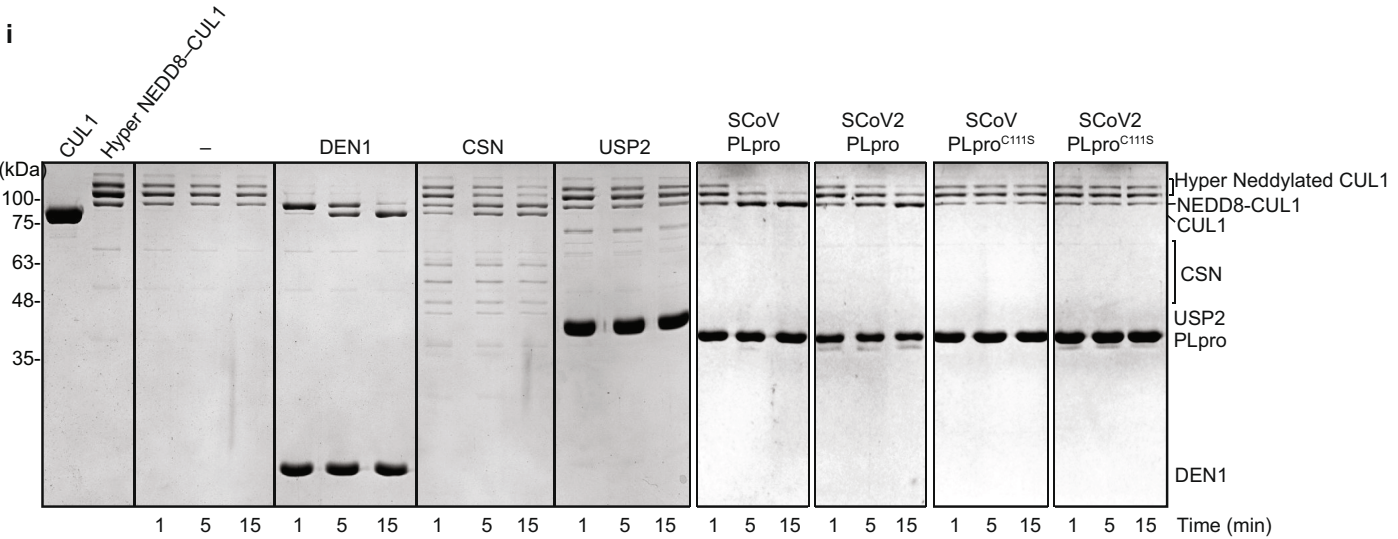

e ISG15-AMC clevage
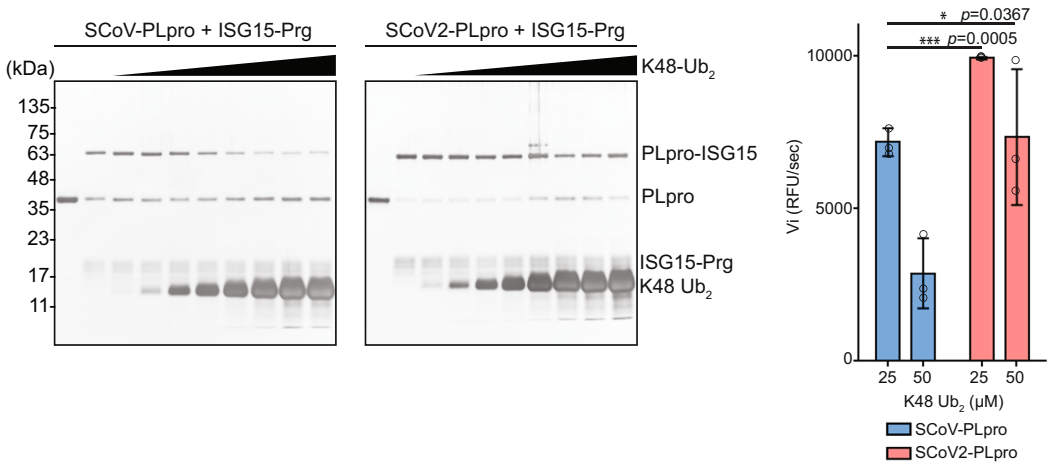

g

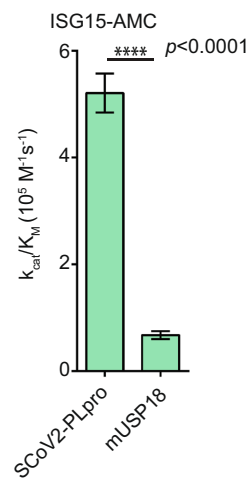

h

PLpro clevage site

SARS-CoV2 nsp1/2 -NTK-HSSGVTRELMREINGGAYT SARS-CoV2_nsp2/3 -CAL-APNMMVTNNTETIKGGAPT SARS-COV2_nsp3/4 -CATTRQVVNVVTTKIAIKGGKIV hUbiquitin -SDYNIQKESTLHLVLRIRGG-hISG15 -GEYGLKPLSTVFMNLRIRGG-hNEDD8 -ADYKILGGSVLHLVLAIRGG-hSUMO1 -KELGMEEEDVIEVYQEQTGG---

hSUMO2 2 -AOLEMEDEDTIIDVFOQOTGG-

hSUMO2 -AQLEMEDEDTIDVFQQQTGG---

Extended Data Fig. 1 | See next page for caption. 
Extended Data Fig. 1 | Biochemical properties of SCoV2-PLpro. a, Sequence similarity of PLpro from SARS, MERS and SARS-CoV-2. $\mathbf{b}$, IFN- $\alpha$-treated HeLa cell lysates were incubated with PLpro for indicated time points and analysed by immunoblot c, Propargylamide-activity based probes of ubiquitin like modifiers were reacted with (left) SCoV-PLpro (right) $\mathrm{PLpro}^{\mathrm{Cov} 2}$. d, ISG15-Prg were incubated with SCoV-PLpro (left) or SCoV2-PLpro (right) with increasing amount of non-hydrolysable $\mathrm{K} 48-\mathrm{Ub}_{2}$.e, Initial AMC release rate from ISG15AMC. Purified SCoV-PLpro and SCoV2-PLpro were incubated with ISG15-AMC and indicated amounts of $\mathrm{K} 48-\mathrm{Ub}_{2}$. The release of $\mathrm{AMC}$ was measured by increase of fluorescence at (Ex./Em.360/487 nm).f, Purified mUSP18 (left) and SCoV2-PLpro (right) were incubated with ISG15-propargylamide activity-based probes for indicated time points. $g$, Catalytic efficiency $\left(k_{\mathrm{cat}} / K_{\mathrm{m}}\right)$ of mUSP18 and SCoV2-PLpro on ISG15-AMC cleavage. $h$, Sequence alignment of PLpro cleavage site of Nsp1/2, Nsp2/3, Nsp3/4 from SARS-CoV2 and human ubiquitin like modifiers. i, Hyper-NEDDylated CUL1-RBX1 was incubated with purified PLpro proteins for indicated time points at $37^{\circ} \mathrm{C}$. Reactions were performed side-byside by with well-characterized deneddylating enzymes (DEN1 with broad specificity or COP9Signallosome CSN specific for NEDD8 linked directly to a cullin), or the broad specificity deubiquitinating enzyme USP 2 as controls. Data in $\mathbf{e}, \mathbf{g}$ are presented as mean \pm s.d. ( $n=3$, independent experiments).

${ }^{* *} P<0.01,{ }^{* * *} P<0.001,{ }^{* * * *} P<0.0001$; two-tailed paired $t$-tests. Experiments in b-d,f, $\mathbf{i}$ were repeated three times independently with similar results. 


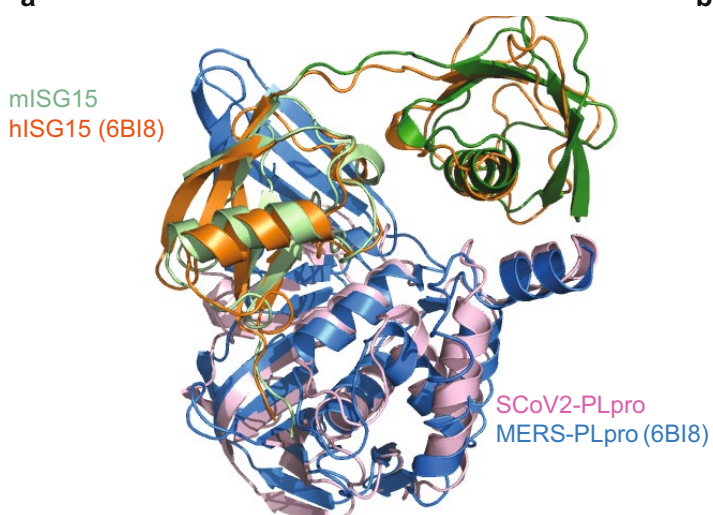

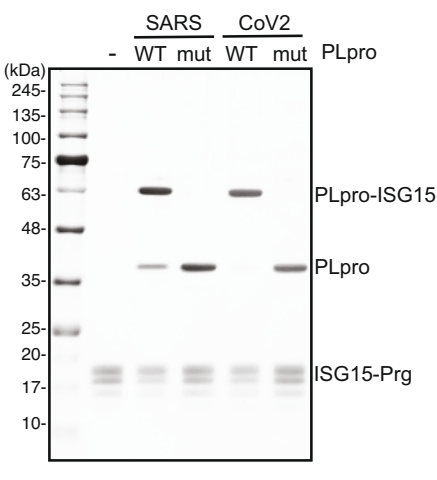

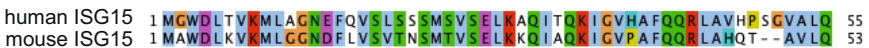
mouse ISG15 1 MAWDLKVKMLGGNDFLVSVTNSMTVSELKKQIAQK I GVPAFQQR LAHQT - -AVLQ

$$
\text { M+WDL+VKML+CN+F+VS+++SM+VSELK+QI+QK IGV+AFQQRLA+++SG++LQ }
$$

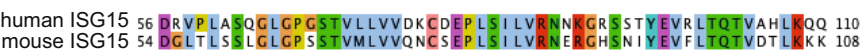
mouse ISG15 54 DGLTLS SLGLGP SSTVMLVVQNCSEP LS I LVRNERGHSN I YEVFLTQTVDTLKKK 10

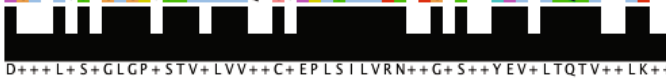

mISG15 C-term with SCoV2-PLpro mISG15 C-term with SCoV-PLpro (5TL7)

SCoV2-PLpro

SCoV-PLpro

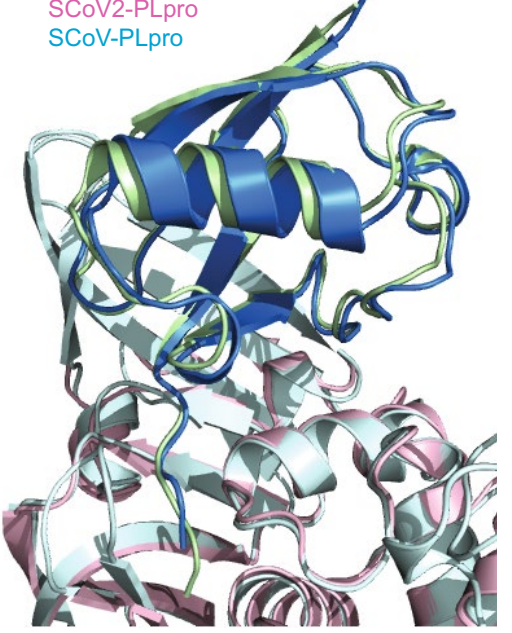

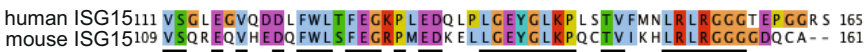

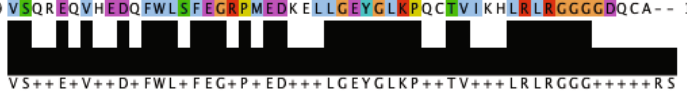

Identity: $63 \%$, Similiarity: $73 \%$

d

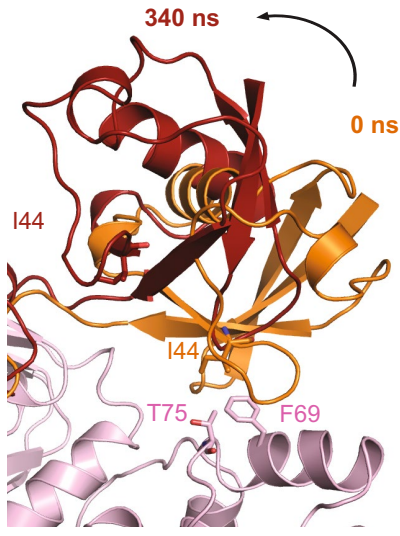

e

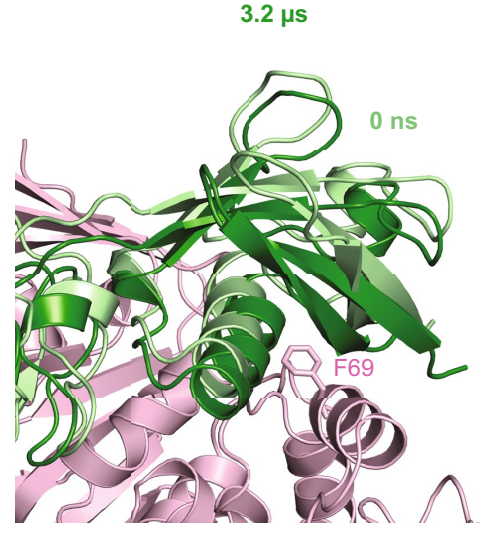

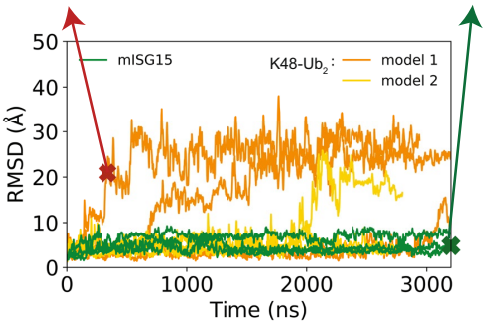

Extended Data Fig. 2 | Complex structure of SCoV2-PLpro with mouseISG15. a, Structural comparison of mouseISG15:SCoV2-PLpro with humanISG15: MERS-PLpro (PDB: $6 \mathrm{BI}^{16}$ ) and sequence alignment of human and mouse ISG15. b, Activity test of wild type or catalytically inactive mutant (C111S) of SCoV-PLpro and SCoV2-PLpro. ISG15 Propargyl-activity based probes were mixed with indicated PLpro proteins. Experiments were repeated three times independently with similar results.c, Structural comparison of C-terminal domain of ISG15 in complex with SCoV2-PLpro and SCoV-PLpro (PDB: 5TL7 ${ }^{17}$ ). d, Snapshots from molecular dynamics simulations of SCoV2-PLpro (light pink cartoon) with (left) $\mathrm{K} 48-\mathrm{Ub}_{2}$ at $340 \mathrm{~ns}$ and (right) mISG15 at $3.2 \mu \mathrm{s}$. Key residues in the interface are highlighted.e, Backbone r.m.s.d. of the $\mathrm{N}$-terminal domain of mISG15 (green) and of the distal ubiquitin in K48-Ub ${ }_{2}$ in an apo-like model

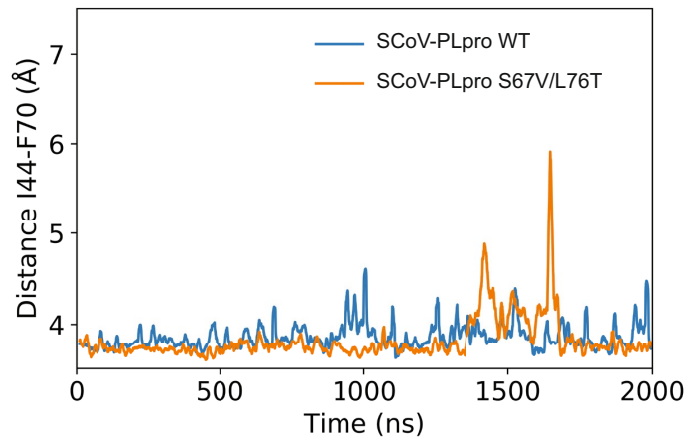

g

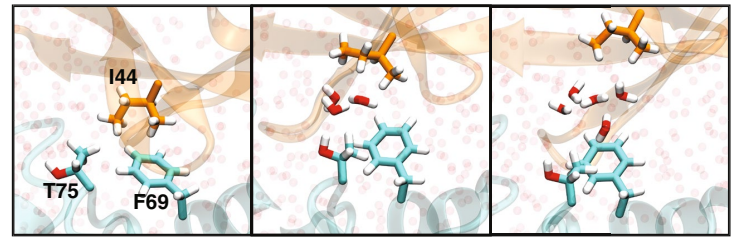

(orange, model1, SCoV2-PLpro coordinates from substrate unbound form, PDB: 6W9C) and in an mISG15-like model (yellow, model 2, SCoV2-PLpro coordinates from substrate bound form, $\mathrm{PDB}$ : 6YVA) from their respective SCoV2-PLpro-bound starting structures as function of time. The r.m.s.d. was calculated after superimposing the helix backbone atoms of SCoV2-PLpro. Time points for structural snapshots in e) are marked with a cross.f, Minimum heavy atom distance between F70 (SARS) and I44(Ub) in wild type and double mutant (S67V/L76T) of SCoV-PLpro:K48-Ub ${ }_{2}$ as function of time.g, Water mediated dissociation pathway. Left, initial hydrophobic interactions between F69(CoV2), T75(CoV2) and I44(Ub). Middle, water wedges in between T75(CoV2) and I44(Ub). Right, water penetration between T75(CoV2)/F69 (CoV2) and I44(Ub) leads to dissociation. 
$\nabla$ Catalytic triad

$\nabla$ Key residues on S2-binding sites

$\nabla$ GRL-0617 binding site

SARS-CoV-2
SARS
MERS
hCoV_OC43
hCoV_229E
hCoV_NL63
mHepatitisV
bCoV

Consensus

SARS-CoV-2

SARS

MERS

hCoV_OC43

hCoV_229E

hCoV_NL63

mHepatitisV

bCoV

Consensus

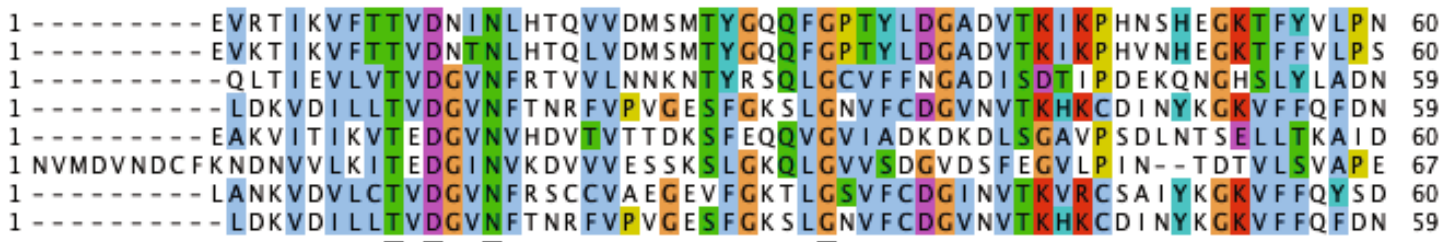

1 -

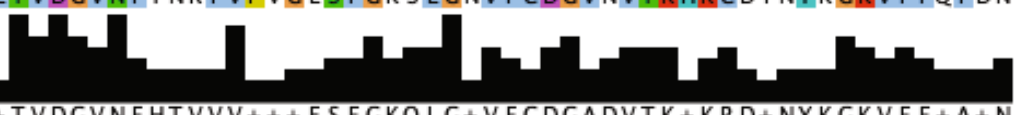

NVMDVNDCFE+D++DVL+TVDGVNFHTVVV+++ESFGKQLG+VFCDGADVTK+KPD+NYKCKVFF+A+N

61 DDTLRVEA EY YHTTDP LGR YMSALNHTKKWKYPQVNGLTSIKWADNNCYLATAL广TLQQ I- ELKF 127 61 DDTLRSEA F EY - YHTLDESFLCRYMSA LNHTKKWK FPQVGGLTS I KWADNNCYLSSVLLA LQQ L- EVKF 127 60 LTADETKALKELYGPVDPT FLHR FYSLKAAVHGWKMVVCDKVRSLKLSDNNCYLNAVIMTLDLLKDIKF 128 60 LS SEDLKAVRS-SFNFDQKELLAYYNMLVNCFKWQVVVNCKYFTFKQANNNCFVNVSCLMLQSL-HLTF 126 61 VDWVEFYGFKD- - - - A A T FATVDHSAFAYESAVVNG I RVLKTSDNNCWVNAVCIALQYS-KPHF 119 68 VDVIVAFYGFEK- - - - - AALFASLDVKPYGYPNDFVGGFRVLGTTDNNCWVNATCIILQYL-KPTF 126 61 LS EADLVAVKD-AFGFDEPQLLKYYTMLGMC-KWSVVVCGNYFAFKQSNNNCYINVACLMLQHL-SLKF 126 60 LSSEDLKAVRS-SFNFDQKELLAYYNMLVNCSKWQVVFNGKYFTFKQANNNCFVNVSCLMLQSL-NLKF 126

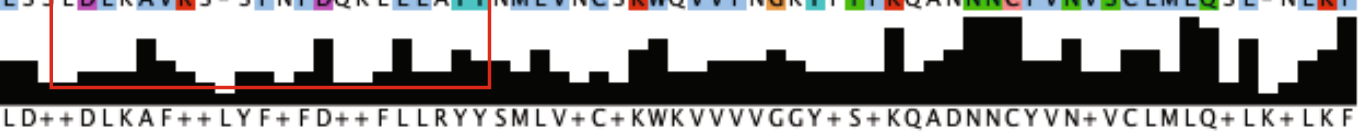

5 ARS-COV-2

SARS

MERS

hCoV_OC43

hCoV_229E

hCoV_NL63

mHepatitisV

bCoV

Consensus

128 NPPALQDAYYRARACEAANFCALI LAYCNKTVGELGDVRETMSYLFQHANLDS-CKRVLNVVCKTCGQQ 195 128 NAPA LQEAYYRARACDAANFCALI LAYSNKTVGELCDVRETMTHLLQHANLES-AKRVLNVVCKHCGQK 195 $129 \mathrm{~V}$ I P A LQHAFMKHKGGDSTDF I A L I MAYCNCT FCAPDDASR LLHTVLAKAELCCSARMVWR EWCNVCC I K 197 $127 \mathrm{~K}$ I VQWQEAWLEFR SGRPAR FVALVLAKCGFKFCDPADSRDFLRVVFSQVDLTC-A I CDFE I ACK-CGVK 193 120 I SQG LDAAWNK FV LCDVE I FVAFVYYVAR LMKCDKCDAEDTLTKLSKYLANEAQVQLEHYSSCVECDAK 188 127 KSKCLNVLWNK FVTCDVGP FVS F I Y F I TMSS KCQKCDAEEALSKLSEYLISDS I VTLEQYSTCDICKS- 194 127 PKWQWQ EAWNEFRSGKP LRFVSLVLAKCSFKFNEPSDS I DFMRVVLREADLSC-ATCNLEFVCK-CGVK 193 127 K I VQWQEAWLEFRSGRPAR FVSLVLAKCGFKFGDPADSRDFLRVVFSQVDLTC-A I CDFEIACK-CGVK 193

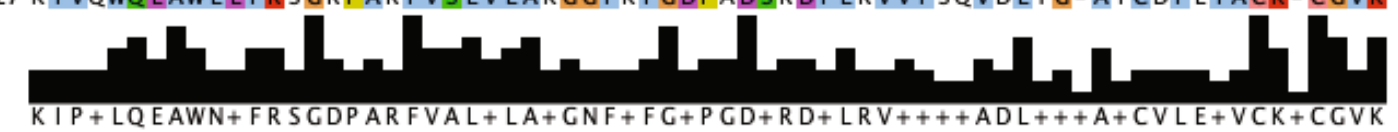

SARS-COV-2

SARS

MERS

hCOV_OC43

hCoV_229E

hCoV_NL63

mHepatitisV

bCoV

Consensus

196 QT T - LKCVEAVMYMCTLSYEQFKKCVQI PCTCGKQATKYLVQQESPFVMMSAPPAQYELKHCT - - - FTC 260 196 TT T - LTCVEAVMYMCTLSYDNLKTGVS I PCVCGRDATQYLVQQESSFVMMSAPPAEYK LQQCT - - F LC 260 198 DVV - LQG LKACCYVCVQTVEDLRARMTYVCQCGCERHRQLVEHTTPWLLLSCTPNEKLVTTSTAPDFVA 265 194 Q EQ - R T C LDAVMHFCTLSR EDLE I GYTVDCSCGKKL I H-CVR FDVP FL I CSNTPASVKLPKCV---GS- 256 189 FKNSVAS INSA I VCA SVKRDCVQVGY---CVHCI KYYS-RVR SVR CRA I IVSVEQLEPCAQSRLLSCVA 253 195 - - - TVVEVKSA IVCA SVLKDGCDVGF- - CP HRHKLRS-RVKFVNGRVVITNVGEPIISQPSKLLNGIA 256 194 Q EQ-RKCVDAVMHFCTLDKCDLVRGYNI ACTCCSKLVH-CTQFNVPFLICSNTPECRKLPDDV-- - VA- 256 194 Q EQ-RTGVDAVMHFGTLSREDLE I GYTVDCSCGKKLIH-CVRFDVPFLICSNTPASVKLPKCV-- - CS- 256

\section{1}

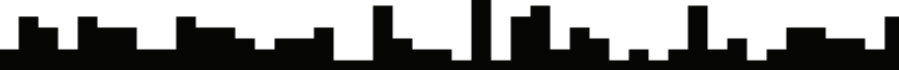

QEQ++TGVDAVM+FGTLSREDL++CYT I+C+CGKKL+HY+V+F+VPFLICSNTPA++KLP+C+LL+C+A

SARS-COV-2

SARS

MERS

hCoV_OC43

hCoV_229E

hCoV_NL63

mHepatitisV

bCoV

261 ASEYTG-NYQCGHYKHITSKETL-YCI DGALLTKSSEYKGPITDVFYKENSYTTTIK-- - - -

261 ANEYTC-NYQCGHYTHITAKETL-YR I DGAHLTKMSEYKGPVTDVFYKETSYTTTIK-- - - -

266 FNVFQG I ETAVGHYVHAR LKGGLI LKFDSGTVSKTSDWKCKVTDVLFPGQKYSSDCN- - - - -

257 AN I FI C- - DKVGHYVHVKCEQSY-QLYDASNVKKVTDVTCKLSDCLYLKNLKQTFKSVLTTYY-

254 YTAF SC-PVDK - HYT TYDTAKKS--MYDCDR FKHDLSLLSVTSVVMVGCYVAPVNTVK- - - -

257 YTT F SC-SFDNGHYVVYDAANNA- - VYDCAR LFSSDLSTLAVTAIVVVGCCVTSNVPTIVSEK-

257 AN I FTG- - CSVGHYTHVKCKPKY - Q LYDACNVNKVSEAKCNFTDCLYLKNLKQTFSSVLTTFYL

257 AN I FKG - - DKVGHYVHVKCEQSY-QLYDASNVKKVTDVTCNLSDCLYLKNLKQTFKSVLTTYY -

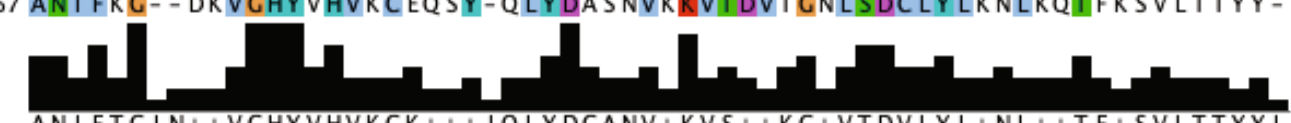

Consensus
Extended Data Fig. 3 |Sequence alignment of papain like protease domain from corona viruses. The amino acid sequences of papain-like protease domain from eight different coronaviruses (SARS-CoV-2, SARS, MERS, humanCoV-OC43, humanCoV-229E, humanCoV-NL63, murine HepatitisV, bovine $\mathrm{CoV}$ ) were aligned with Clustal Omega. Accession numbers: SARS-CoV-2 (NC_045512), SARS (PDB:3MJ5), MERS (PDB: 5W8U), hCoV-OC43 (AY585228), hCoV-229E (X69721), hCoV-NL63 (NC_005831), murine HepatitisV (NC_001846), bCoV (NC_003045). 
a

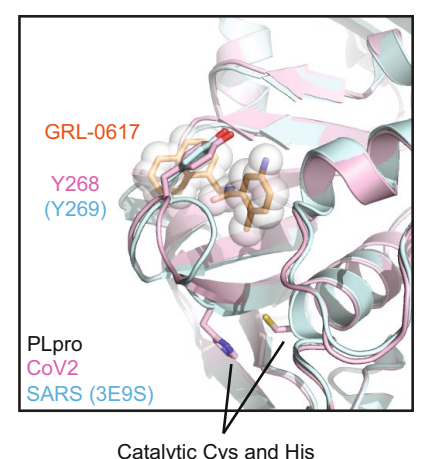

Catalytic Cys and His b

CoV2 with GRL-0617 $\quad \mathbf{1} \boldsymbol{\mu s}$

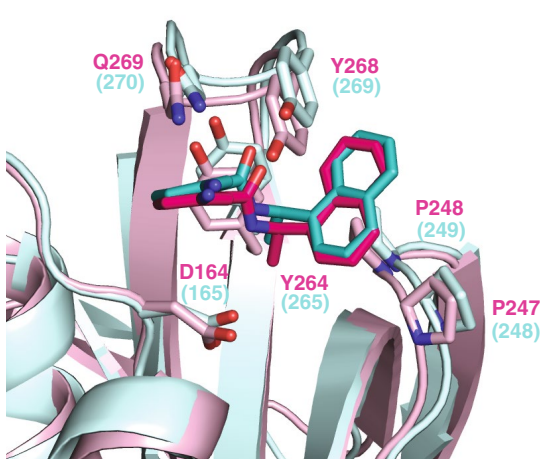

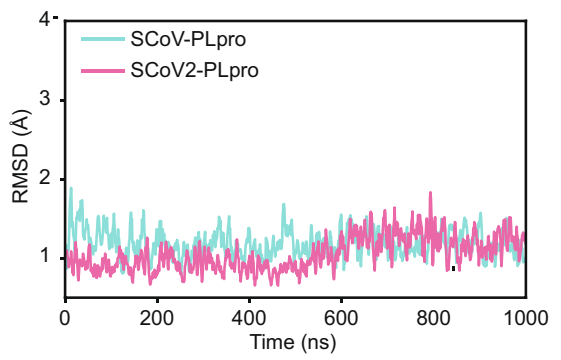

d

Substrate:Ubiquitin-AMC
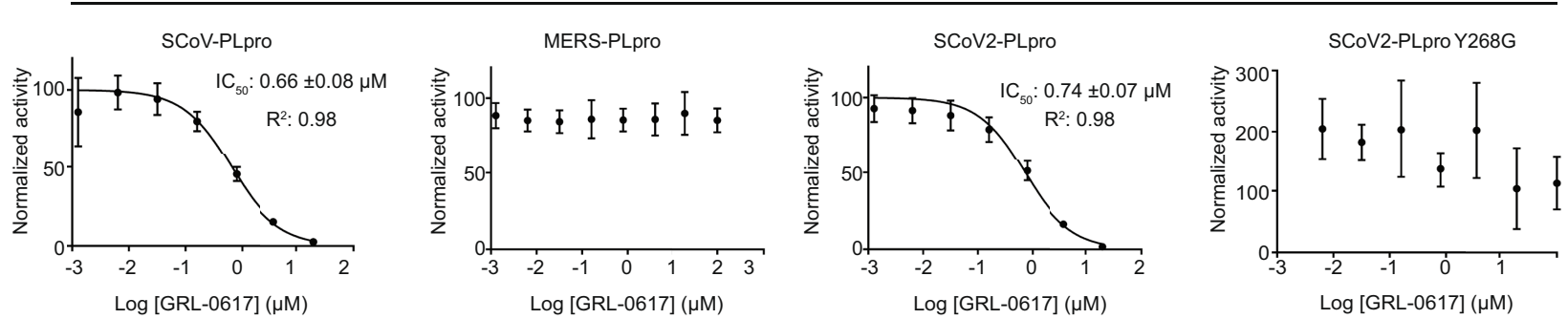

e
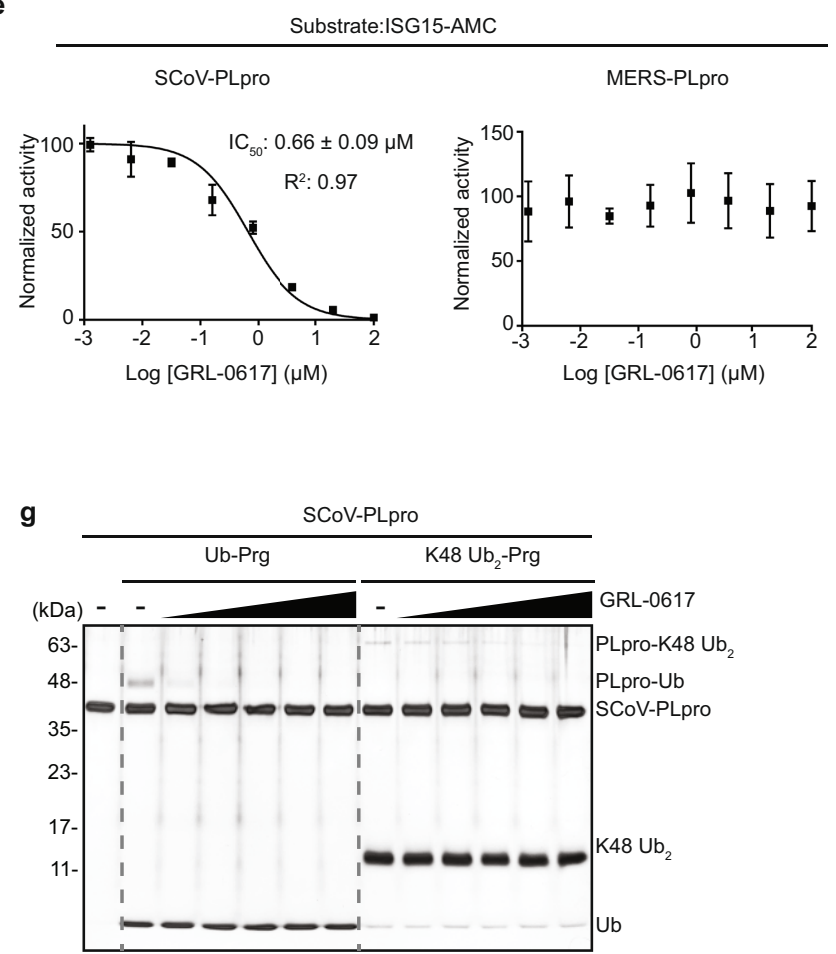

h
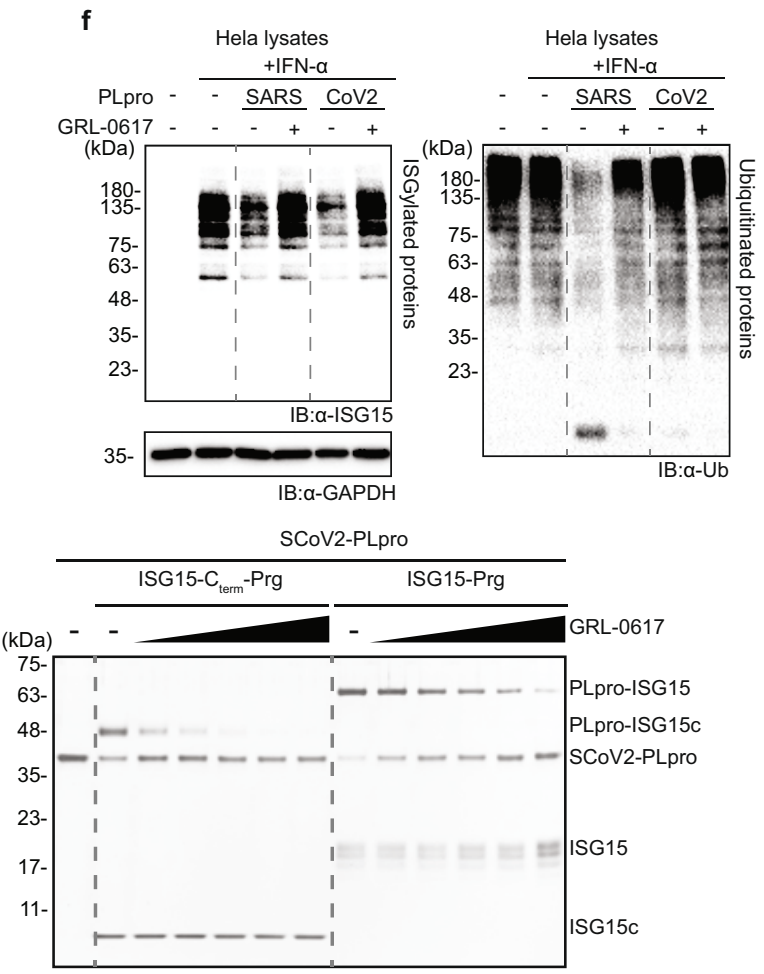

Extended Data Fig. 4 | See next page for caption. 
Extended Data Fig. 4 | Structural analysis of GRL-0167, SCoV2-PLpro complex. a, Structural model of GRL-0617 bound SCoV2-PLpro. The conformation of Tyr 268 on SCoV2-PLpro and the coordinates of GRL-0617 is obtained from the SCoV-PLpro:GRL-0617 structure $\left(\mathrm{PDB}: 3 \mathrm{ESS}^{18}\right)$ b, Snapshots of SCoV-PLpro (light cyan) and SCoV2-PLpro (light pink) with bound GRL-0617 (dark colours) after $1 \mu$ s of molecular dynamics simulation. The protein backbones are shown in cartoon representation, and the ligand with contacting residues as sticks. c, r.m.s.d. of the GRL-0617 bound to SCoV-PLpro (light blue) and SCoV2-PLpro (light pink) as a function of time. The r.m.s.d. was calculated for non-hydrogen atoms of GRL-0617 with respect to the starting structures in the MD simulations after superimposing the helix backbone atoms of PLpro. d, In vitro PLpro inhibition assay. Initial velocity of AMC release from ubiquitin-AMC in different concentration of GRL-0617 was measured and normalized to DMSO control. IC ${ }_{50}$ value of GRL-0617 to SCoV-PLpro and SCoV2-
PLpro were presented. Data are presented as mean \pm s.d. $(n=3$, independent experiments). e, In vitro PLpro inhibition assay. Initial velocity of AMC release from ISG15-AMC in different concentration of GRL-0617 was measured and normalized to DMSO control. IC $_{50}$ value of GRL-0617 to SCoV-PLpro were presented. Data are presented as mean \pm s.d. ( $n=3$, independent experiments). f, Effects of GRL-0617 on (left) deISGylase or (right) deubiquitinase activity of PLpro of SARS and SARS-CoV-2.g, Effects of GRL-0617 on SCoV-PLpro activity to (left) ubiquitin or (right) $\mathrm{K} 48-\mathrm{Ub}_{2}$ propargyl activity-based probes. Inhibitory effect of GRL-0617 on ubiquitin species was tested with various concentration of GRL-0617 (0-400 $\mu \mathrm{M})$. h, Effects of GRL-0617 on SCoV2-PLpro activity to (left) ISG15- $\mathrm{C}_{\text {term }}$ or (right) ISG15 propargylamide activity-based probes. Inhibitory effect of GRL-0617 on ISG15 was tested with various concentration of GRL-0617 (0-400 $\mu \mathrm{M})$. Experiments in $\mathbf{f}-\mathbf{h}$ were repeated three times independently with similar results. 


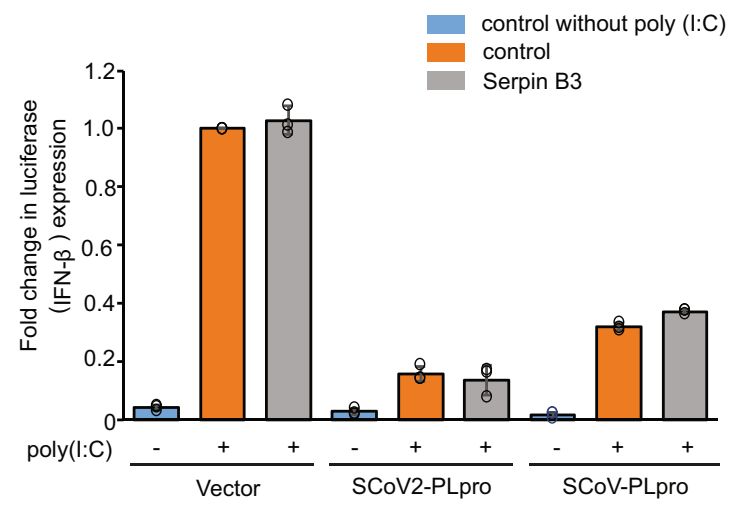

c

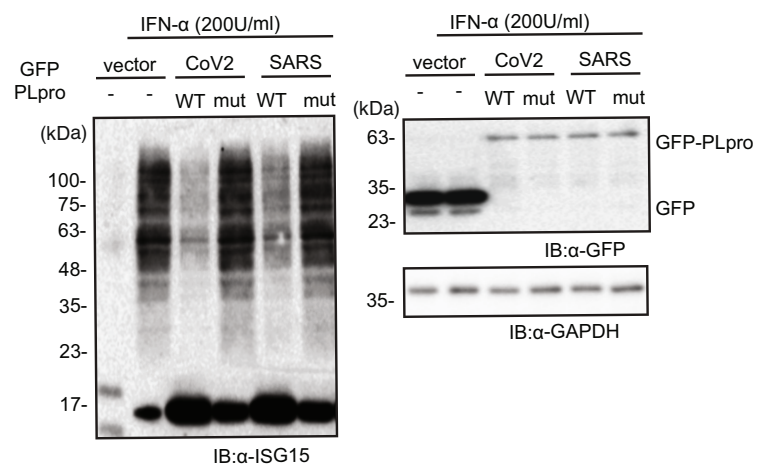

e

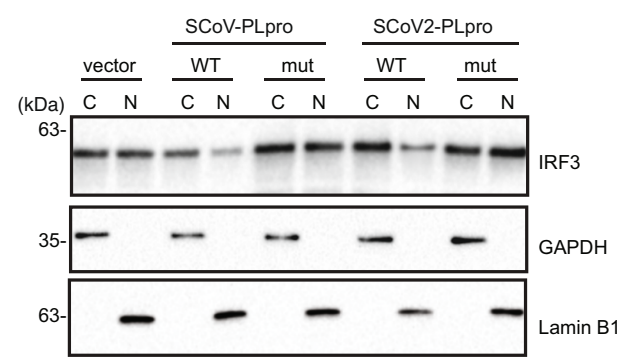

g

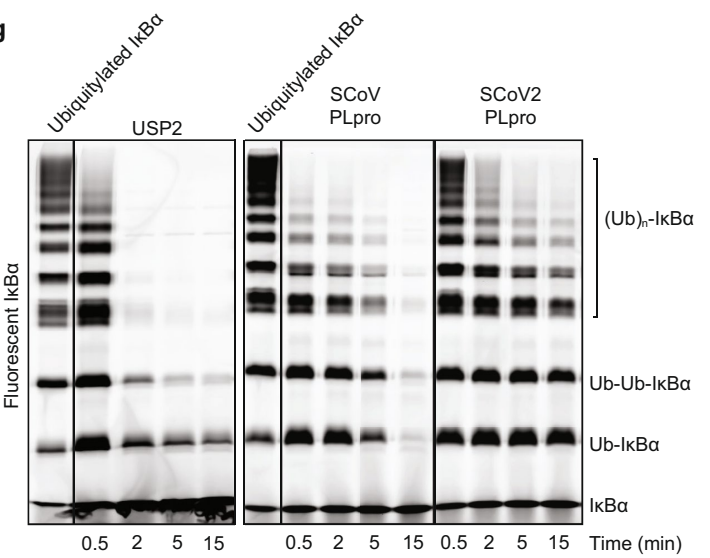

b

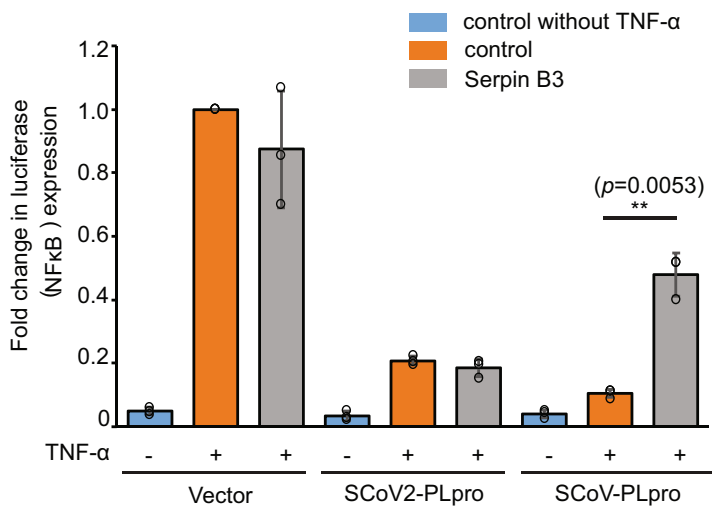

d
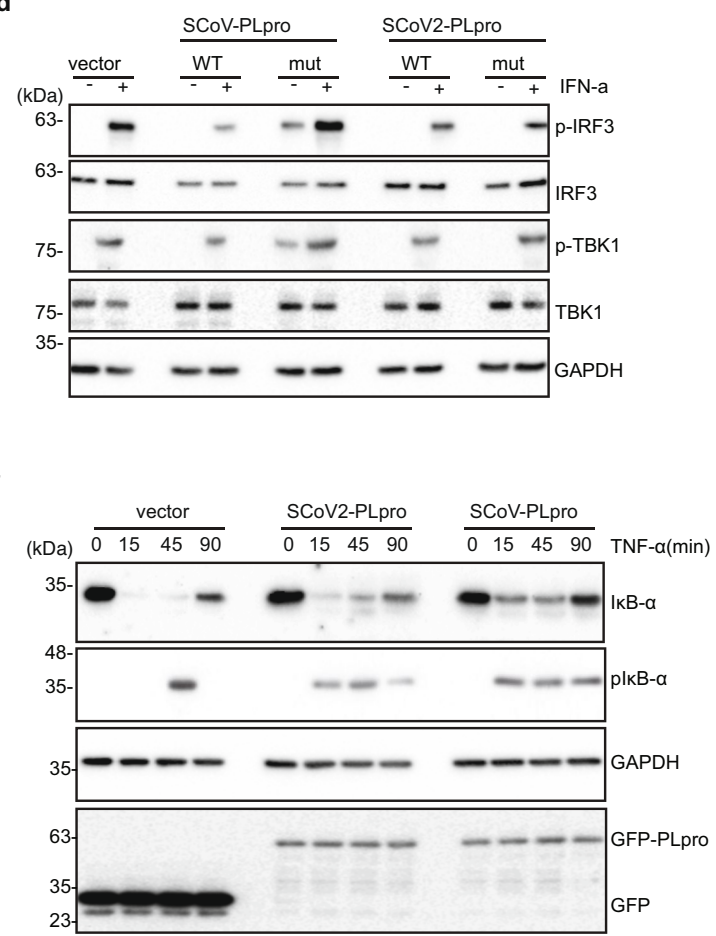

h

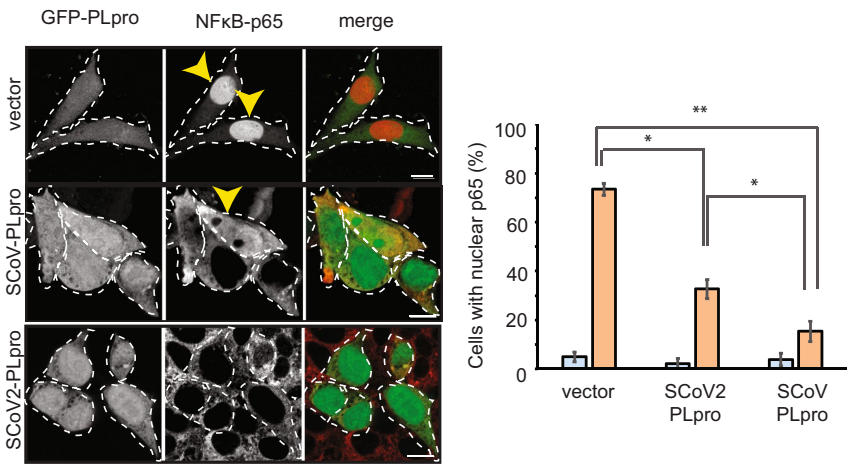

Extended Data Fig. 5 | See next page for caption. 
Extended Data Fig. 5 | Physiological roles of PLpro in cells. a, b, Effect of SERPIN B3 on PLpro mediated IFN- $\beta$ (a) or NF-KB p65 (b) expression level. A549 Cells were co-transfected with indicated GFP-PLpro and Myc-SERPINs and treated with either poly(I:C) or TNF- $\alpha$ to induce IFN- $\beta$ and NF-KB p65 expression, respectively. Fold changes of luciferase level are presented.c, Effect of PLpro on IFN-induced cellular ISGylation. A549 cells were transfected with indicated PLpro plasmids and treated with IFN- $\alpha$. Lysates were analysed by immune-blotting with indicated antibodies. d, e, Effect of PLpro on IFNsignalling pathway. d, A549 cells were transfected with indicated PLpro plasmids and treated with IFN- $\alpha$. Lysates were analysed by immune-blotting with indicated antibodies. e, Effect of PLpro on cellular localization of IRF3. Cells from d were fractionated into cy tosol and nucleus and the level of IRF3 was analysed. Lamin B1 was used for nuclear fraction control.f, Effect of PLpro on the NF-kB pathway. IкB- $\alpha$ phosphorylation and degradation were examined from A549 cells expressing indicated GFP-PLpro under treatment of TNF- $\alpha$. $\mathbf{g}$, in vitro IKB $\alpha$ deubiquitylation assay. Ubiquitinated I $\mathrm{KB} \alpha$ were incubated with SCoV-PLpro or SCoV2-PLpro. USP2 were used as positive control. $\mathbf{h}$, Effect of PLpro on NF-kB p 65 cellular localization. Scale bar, $10 \mu \mathrm{m}$. Data in $\mathbf{a}, \mathbf{b}, \mathbf{h}$ are presented as mean \pm s.d. $\left(n=3\right.$, independent experiments). ${ }^{*} P<0.05,{ }^{* *} P<0.01$; two-tailed paired $t$-tests. Experiments in $\mathbf{c}-\mathbf{h}$ were repeated three times independently with similar results. e, Effect of PLpro on the NF-KB pathway. IкB- $\alpha$ phosphorylation and degradation were examined from A549 cells expressing indicated GFP-PLpro under treatment of TNF- $\alpha$. 
a

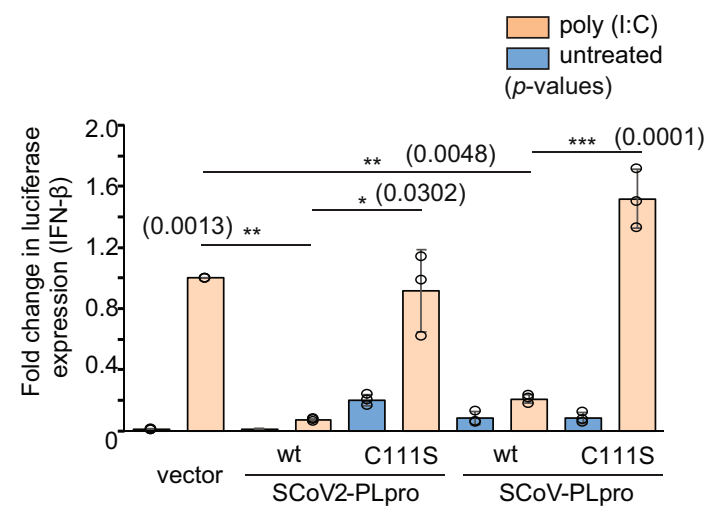

c

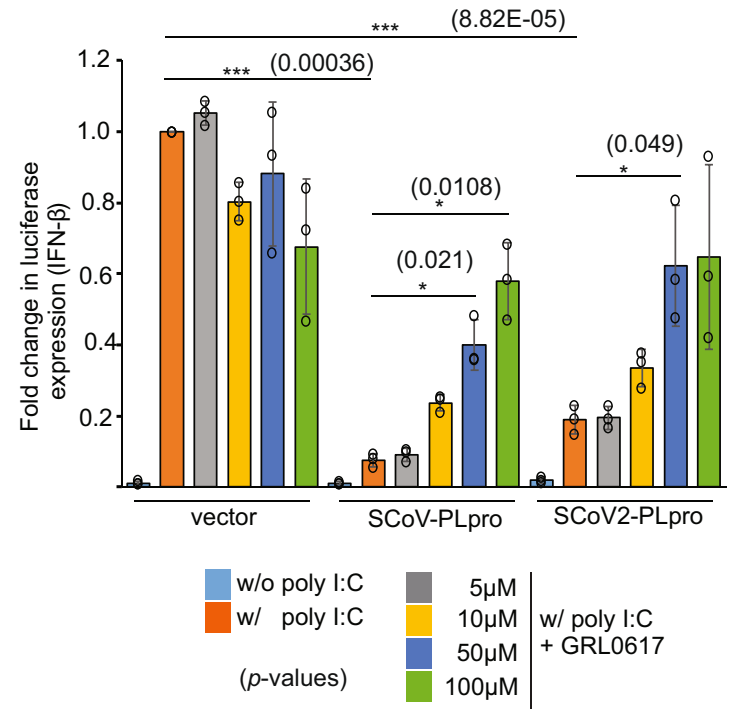

Extended Data Fig. 6 | Effect of PLpro on IFN- $\beta$ or NF-kB p65 expression level. a, b, Effect of PLpro on IFN- $\beta$ (a) or NF-KB p65 (b) expression level. A549 Cells were transfected with indicated GFP-PLpro and treated with either poly(I:C) or TNF- $\alpha$ to induce IFN- $\beta$ and NF-KB p 65 expression, respectively. c, d, Effect of GRL-0617 on PLpro mediated IFN- $\beta$ (c) or NF-KB p65 (d) expression b

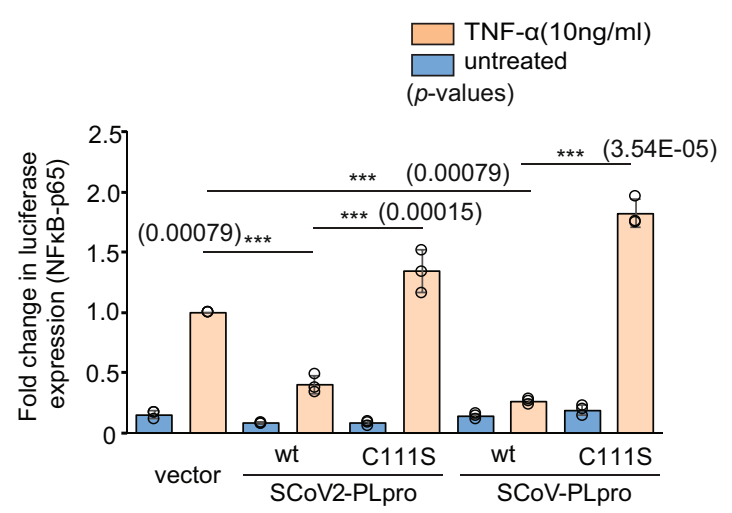

d

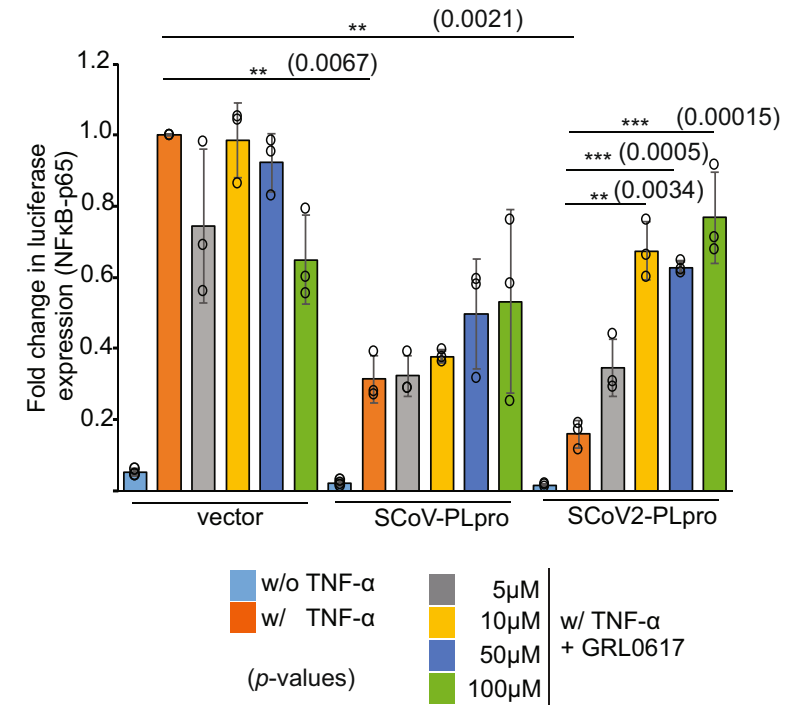

level. A549 Cells were transfected with indicated GFP-PLpro and treated with either poly (I:C) or TNF- $\alpha$ to induce IFN- $\beta$ and NF-KB p65 expression, respectively. GRL-0617 is treated as indicated. All data are presented as mean \pm s.d. $\left(n=3\right.$, independent experiments). ${ }^{*} P<0.05,{ }^{* *} P<0.01,{ }^{* * *} P<0.001$; two-tailed paired $t$-tests. 
a

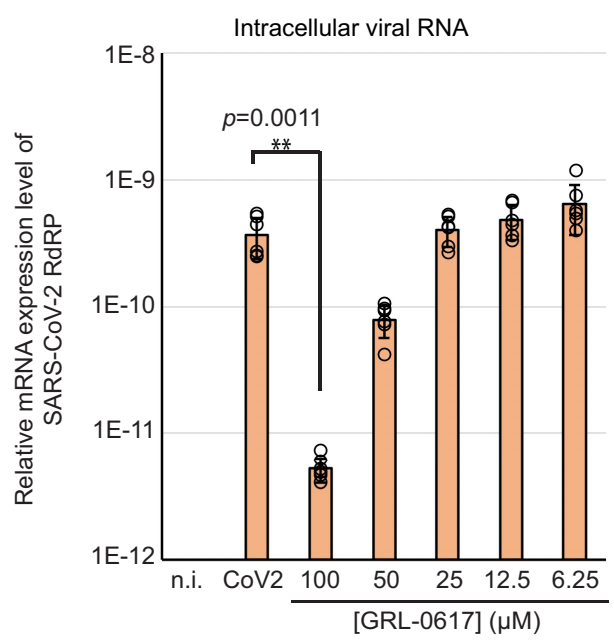

b

untreated

GRL-0617(25uM)

( $p$-values)
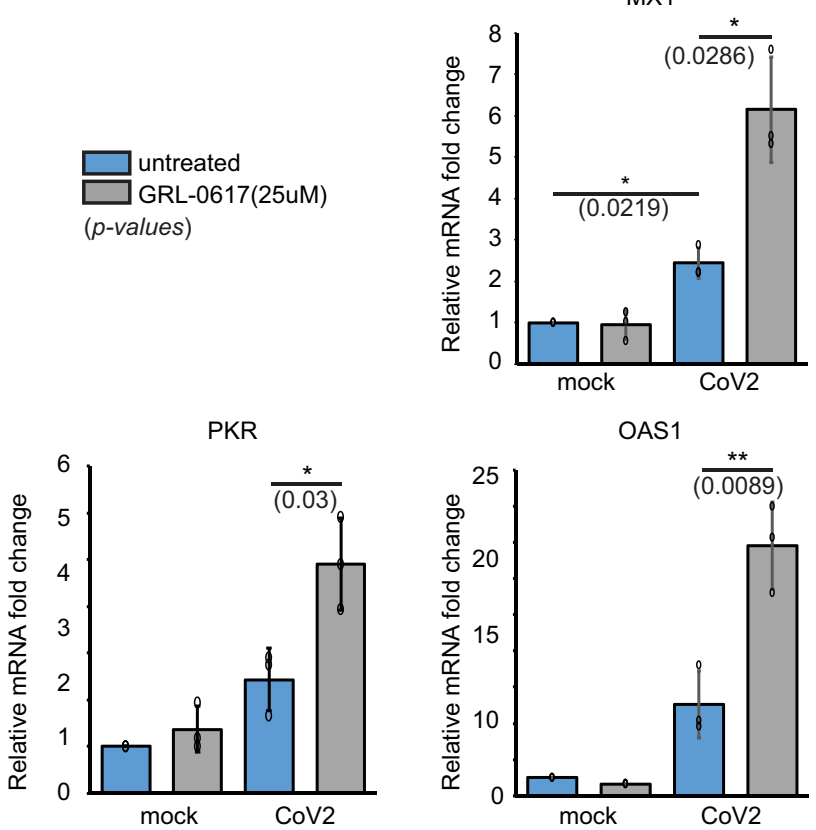

c

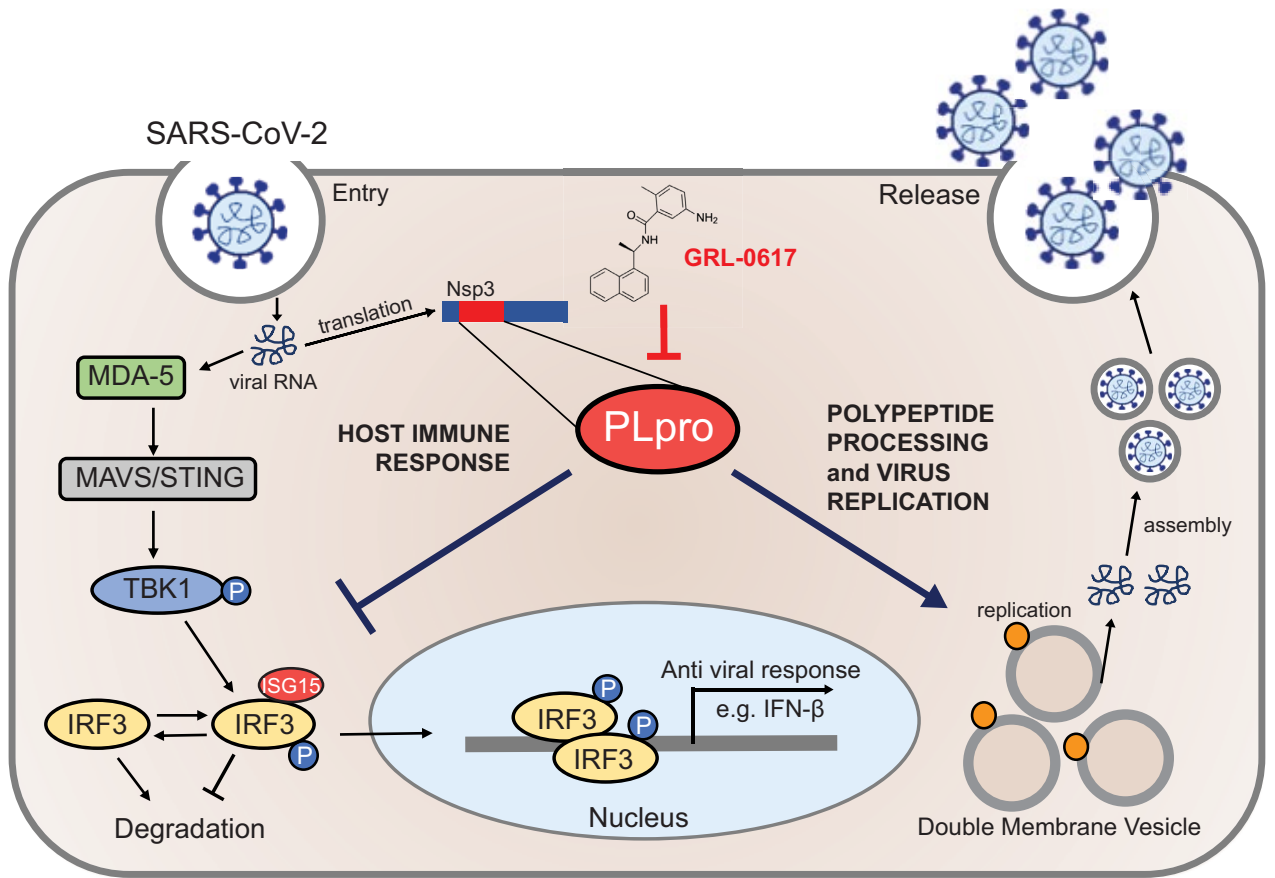

Extended Data Fig. 7 | Inhibitory effects of GRL-0617 on SARS-CoV2 infection. a, Intracellular virus production was analysed by PCR targeting SARS-CoV-2 RdRP mRNA. Relative expression level of SARS-CoV2-2 genomic RNA was normalized to cellular GAPDH level. $\mathbf{b}$, Intracellular RNA was isolated from cells without infection or cells infected with SARS-CoV-2 with or without treatment of GRL-0617. Relative mRNA-level fold change of indicated genes were analysed in a qRT-PCR analysis and normalized to ACTB levels. Data in a, b are presented as mean \pm s.d. $\left(n=3\right.$, independent experiments). ${ }^{*} P<0.05$, ${ }^{* *} P<0.01$; two-tailed paired $t$-tests. $\mathbf{c}$, Schematic representation of the role of SARS-CoV-2 PLpro in the viral life cycle. The physiological role of SCoV2-PLpro in both host-immune response and polypeptide processing is shown. Inhibition of PLpro by GRL-0617 is also presented. 


\section{Article}

Extended Data Table 1 | Data collection and refinement statistics (molecular replacement)

\begin{tabular}{ll}
\hline & SCoV2-PLpro (C111S): mISG15 (PDB: 6YVA) \\
\hline Data collection & \\
Space group & $\mathrm{P} 6222$ \\
Cell dimensions & \\
$\quad a, b, c(\AA)$ & $157.047,157.047,83.633$ \\
$\alpha, \beta, \gamma\left({ }^{\circ}\right)$ & $90,90,120$ \\
Resolution $(\AA)$ & $45.34-3.185(3.298-3.185)^{\dagger}$ \\
$R_{\text {sym } \text { or } R_{\text {merge }}}$ & $0.05751(0.5689)$ \\
$I / \sigma I$ & $8.58(1.19)$ \\
Completeness $(\%)$ & $99.61(97.77)$ \\
Redundancy & $2.0(2.0)$ \\
& \\
Refinement & \\
Resolution $(\AA)$ & $45.34-3.185(3.298-3.185)$ \\
No. reflections & $10590(1008)$ \\
$R_{\text {work }} / R_{\text {free }}$ & $0.2496 / 0.2902$ \\
No. atoms & 3407 \\
Protein & 3383 \\
Ligand/ion & 1 \\
Water & 23 \\
$B$-factors & 87.60 \\
Protein & 87.72 \\
Ligand/ion & 167.02 \\
Water & 66.67 \\
R.m.s. deviations & \\
Bond lengths $(\AA)$ & 0.004 \\
Bond angles $\left({ }^{\circ}\right)$ & 0.65 \\
\hline
\end{tabular}

Statistics for data collection and refinement are presented. *A single crystal was used for data collection and structure determination. ${ }^{\dagger}$ Values in parentheses are for highest-resolution shell. 


\begin{tabular}{|c|c|c|c|}
\hline & Kinetic Parameter & $\begin{array}{l}\text { Triazole-linked K48- } \\
\mathrm{Ub}_{2} \text {-AMC }\end{array}$ & ISG15-AMC \\
\hline \multicolumn{4}{|l|}{ SARS-CoV-2 } \\
\hline \multirow{4}{*}{ PLpro } & Apparent $\mathrm{k}_{\mathrm{cat}} / \mathrm{K}_{\mathrm{M}}\left[\mathrm{M}^{-1} \mathrm{~s}^{-1}\right]$ & $2.41 \pm 0.94(\mathrm{E}+05)$ & $5.21 \pm 0.36(\mathrm{E}+05)$ \\
\hline & $\mathrm{k}_{\text {cat }}\left[\mathrm{s}^{-1}\right]$ & $14.75 \pm 3.28$ & $4.43 \pm 0.13$ \\
\hline & $\mathrm{K}_{\mathrm{M}}[\mu \mathrm{M}]$ & $61.23 \pm 19.76$ & $8.50 \pm 0.54$ \\
\hline & Michaelis-Menten curve fit $\left(\mathrm{R}^{2}\right)$ & 0.9914 & 0.9987 \\
\hline \multicolumn{4}{|l|}{ SARS } \\
\hline \multirow{4}{*}{ PLpro } & Apparent $\mathrm{k}_{\mathrm{cat}} / \mathrm{K}_{\mathrm{M}}\left[\mathrm{M}^{-1} \mathrm{~s}^{-1}\right]$ & $13.94 \pm 3.50(\mathrm{E}+05)$ & $5.31 \pm 0.56(E+05)$ \\
\hline & $\mathrm{k}_{\text {cat }}\left[\mathrm{s}^{-1}\right]$ & $62.9 \pm 8.45$ & $11.89 \pm 0.75$ \\
\hline & $\mathrm{K}_{\mathrm{M}}[\mu \mathrm{M}]$ & $45.13 \pm 9.57$ & $22.41 \pm 1.89$ \\
\hline & Michaelis-Menten curve fit $\left(\mathrm{R}^{2}\right)$ & 0.9911 & 0.9997 \\
\hline \multirow[t]{4}{*}{ mUSP18 } & Apparent $\mathrm{k}_{\mathrm{cat}} / \mathrm{K}_{\mathrm{M}}\left[\mathrm{M}^{-1} \mathrm{~s}^{-1}\right]$ & & $0.68 \pm 0.07(E+05)$ \\
\hline & $\mathrm{k}_{\text {cat }}\left[\mathrm{s}^{-1}\right]$ & N.D. & $0.06 \pm 0.002$ \\
\hline & $\mathrm{K}_{\mathrm{M}}[\mu \mathrm{M}]$ & & $0.89 \pm 0.093$ \\
\hline & Michaelis-Menten curve fit $\left(\mathrm{R}^{2}\right)$ & & 0.9895 \\
\hline
\end{tabular}

Kinetic parameters for SCoV-PLpro, SCoV2-PLpro and murineUSP18 to triazole-linked K48-Ub2-AMC or ISG15-AMC are presented. Values are presented as mean \pm s.d. $(n=3$, independent experiments). 


\section{Article}

Extended Data Table 3 | Binding kinetics of PLpro to $\mathrm{K}_{48}-\mathrm{Ub}_{2}$ or ISG15

\begin{tabular}{|c|c|c|c|c|c|}
\hline & & $\begin{array}{l}k_{\text {on }} \pm \text { S.E.M } \mathrm{M}^{\mathrm{a}} \\
\left(10^{2} \mathrm{M}^{-1} \mathrm{~s}^{-1}\right)\end{array}$ & $\begin{array}{c}k_{\text {off }} \pm \text { S.E.M }{ }^{\mathrm{a}} \\
\left(10^{-1} \mathrm{~s}^{-1}\right) \\
\end{array}$ & $\begin{array}{c}K_{d} \pm \text { S.E. } \mathrm{M}^{\mathrm{a}} \\
(\mu \mathrm{M})\end{array}$ & $\mathrm{R}^{2 b}$ \\
\hline $\mathrm{CoV} 2$ & Triazole linked $\mathrm{K} 48-\mathrm{Ub}_{2}$ & $158 \pm 8.00$ & $4.30 \pm 0.11$ & $27.28 \pm 1.55$ & 0.99 \\
\hline \multirow[t]{2}{*}{ PLpro } & Human ISG15 & $1530 \pm 52.4$ & $2.15 \pm 0.06$ & $1.41 \pm 0.06$ & 0.99 \\
\hline & Mouse ISG15 & $122 \pm 4.48$ & $0.20 \pm 0.02$ & $1.64 \pm 0.17$ & 0.97 \\
\hline \multirow{3}{*}{$\begin{array}{l}\text { SARS } \\
\text { PLpro }\end{array}$} & Triazole linked K48-Ub2 & $820 \pm 32.1$ & $0.81 \pm 0.02$ & $0.99 \pm 0.04$ & 0.98 \\
\hline & Human ISG15 & $88.8 \pm 14.5$ & $0.76 \pm 0.06$ & $8.60 \pm 1.56$ & 0.98 \\
\hline & Mouse ISG15 & $24.7 \pm 0.75$ & $0.23 \pm 0.01$ & $9.34 \pm 0.41$ & 0.98 \\
\hline
\end{tabular}

Binding kinetic parameters for SCoV-PLpro, SCoV2-PLpro to triazole-linked K48-Ub2, humanISG15 or mouseISG15 are presented. Values are presented as mean \pm s.e.m. ( $n=3$, independent experiments). ${ }^{\text {as.e.m. }}{ }^{\mathrm{b}} R^{2}$, goodness of the curve fit between experimental data and mathematical 1:1 binding curve 


\section{natureresearch}

Corresponding author(s): Ivan Dikic

Last updated by author(s): Jul 17, 2020

\section{Reporting Summary}

Nature Research wishes to improve the reproducibility of the work that we publish. This form provides structure for consistency and transparency in reporting. For further information on Nature Research policies, see Authors \& Referees and the Editorial Policy Checklist.

\section{Statistics}

For all statistical analyses, confirm that the following items are present in the figure legend, table legend, main text, or Methods section.

n/a Confirmed

$\square \bigotimes$ The exact sample size $(n)$ for each experimental group/condition, given as a discrete number and unit of measurement

$\square \bigotimes$ A statement on whether measurements were taken from distinct samples or whether the same sample was measured repeatedly

The statistical test(s) used AND whether they are one- or two-sided

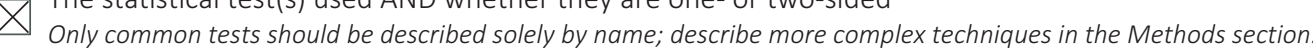

$\bigotimes \square$ A description of all covariates tested

$\bigotimes \square$ A description of any assumptions or corrections, such as tests of normality and adjustment for multiple comparisons

$\triangle$ A full description of the statistical parameters including central tendency (e.g. means) or other basic estimates (e.g. regression coefficient)

$\triangle$ AND variation (e.g. standard deviation) or associated estimates of uncertainty (e.g. confidence intervals)

$\varnothing$ For null hypothesis testing, the test statistic (e.g. $F, t, r$ ) with confidence intervals, effect sizes, degrees of freedom and $P$ value noted

Give $P$ values as exact values whenever suitable.

Х $\square$ For Bayesian analysis, information on the choice of priors and Markov chain Monte Carlo settings

Х For hierarchical and complex designs, identification of the appropriate level for tests and full reporting of outcomes

Х $\square$ Estimates of effect sizes (e.g. Cohen's $d$, Pearson's $r$ ), indicating how they were calculated

Our web collection on statistics for biologists contains articles on many of the points above.

\section{Software and code}

Policy information about availability of computer code

Data collection

Image lab software 5.2.1

Data analysis

Image lab software 5.2.1,Prism5, MaxQuant 1.6.5, Perseus 1.6.5, Pymol (1.7.6.0), phenix (1.17.1-3660), ccp4 (7.0.078), coot (0.8.9.2),

Modeller (9.24), Gromacs (2019.6)

For manuscripts utilizing custom algorithms or software that are central to the research but not yet described in published literature, software must be made available to editors/reviewers. We strongly encourage code deposition in a community repository (e.g. GitHub). See the Nature Research guidelines for submitting code \& software for further information.

\section{Data}

Policy information about availability of data

All manuscripts must include a data availability statement. This statement should provide the following information, where applicable:

- Accession codes, unique identifiers, or web links for publicly available datasets

- A list of figures that have associated raw data

- A description of any restrictions on data availability

The atomic coordinates of PLpro-ISG15 (murine) have been deposited in the PDB with accession code 6YVA in the Protein Data Bank. The mass spectrometry proteomics data have been deposited to the ProteomeXchange Consortium73 via the PRIDE partner repository74 with the dataset identifier PXD018983. The papain-like protease domain sequence is obtained from SARS-CoV-2 complete genome (NCBI genome databank, Severe acute respiratory syndrome coronavirus 2 isolate Wuhan-Hu-1, complete genome; NC_ 045512). Protein sequence for CoV2 PLpro-Ubl domain (amino acids, 746-1060) of Nsp3 protein from SARS-CoV-2 (Nsp3; YP_009725299.1). Full gel images can be found in Supplementary Figure 1 and source data that support this study and can be found in Supplementary Information. Any other relevant data are available from the corresponding authors upon reasonable request. 


\section{Field-specific reporting}

Please select the one below that is the best fit for your research. If you are not sure, read the appropriate sections before making your selection. $\bigotimes$ Life sciences $\quad \square$ Behavioural \& social sciences $\quad \square$ Ecological, evolutionary \& environmental sciences

For a reference copy of the document with all sections, see nature.com/documents/nr-reporting-summary-flat.pdf

\section{Life sciences study design}

All studies must disclose on these points even when the disclosure is negative.

Sample size No sample size calculation was done. Experiments were repeated three times with similar results and sample size was chosen based on the consistency and significance a of measured differences between groups. We have not mentioned any differences between groups if there the differences are not statistically significant.

Data exclusions No data were excluded from analysis.

Replication We have repeated each experiment in the manuscript at least three times to ensure consistent results.

Randomization No randomization was necessary as various infection samples were recorded and analyzed by a computer software for extracting the significant differences.

Blinding Blinding was not relevant for the experiments done as various infection samples were analyzed by a computer software for extracting the significant differences.

\section{Reporting for specific materials, systems and methods}

We require information from authors about some types of materials, experimental systems and methods used in many studies. Here, indicate whether each material, system or method listed is relevant to your study. If you are not sure if a list item applies to your research, read the appropriate section before selecting a response.

Materials \& experimental systems

\begin{tabular}{l|l}
\hline$n / a$ & Involved in the study \\
$\square$ & $\bigotimes$ Antibodies \\
$\square$ & $\square$ Eukaryotic cell lines \\
$\square$ & Animals and other organisms \\
$\square$ & Clinical data
\end{tabular}

\begin{tabular}{l|l}
\multicolumn{2}{l}{ Methods } \\
\hline n/a & Involved in the study \\
$\square$ & $\square$ ChIP-seq \\
$\square$ & $\square$ Flow cytometry \\
$\square$ & $\square$ MRI-based neuroimaging
\end{tabular}

\section{Antibodies}

Antibodies used

Validation

Ubiquitin (Cat\# 3936S, Provider: Cell signaling Technology)
Ubiquitin (Cat\# 3936S, Provider: Cell signaling Technology, 1:2000), ISG15 (Cat\# HPA004627, Sigma Aldrich/Merck, 1:1000), GAPDH (Cat\# 2118, Cell signaling Technology, 1:2000), GFP trap beads (Cat \#: gta-100, Provider: ChromoTek), GFP (Cat\# sc-9996, Santa Cruz Biotechnology, 1:2000), IRF3 (Cat\# 4302, Cell signaling Technology, 1:2000), phospho-IRF3(Ser396) (Cat\# 4947, Cell signaling Technology, 1:1000), IkBa (Cat\# 4812, Cell signaling Technology, 1:2000), phospho-IkBa(Ser32/36) (Cat\# 9246, Cell signaling Technology, 1:1000), TBK1 (Cat\# 3013, Cell signaling Technology, 1:2000), pTBK1 (Cat \# 3300-1 Epitomics, 1:1000), P65 (NFkB) (Cat\# 8008, Santa Cruz Biotechnology, 1:2000), Lamin B1 (Cat\# sc-373918, Santa Cruz Biotechnology, 1:2000).

Validation statement from the manufacturer: Ubiquitin (P4D1) Mouse mAb detects ubiquitin, polyubiquitin and ubiquitinated proteins. This antibody may cross-react with recombinant NEDD8.

Validation found at provider's website: https://www.cellsignal.com/products/primary-antibodies/ubiquitin-p4d1-mouse$\mathrm{mab} / 3936$

ISG15 (Cat\# HPA004627, Sigma Aldrich/Merck)

Validation statement from the manufacturer: species reactivity-human, validation-recombinant expression, orthogonal RNA seq Validation found at provider's website: https://www.sigmaaldrich.com/catalog/product/sigma/hpa004627?lang=en\&region=DE

GAPDH (Cat\# 2118, Cell signaling Technology)

Validation statement from the manufacturer: GAPDH (14C10) Rabbit mAb detects endogenous levels of total GAPDH protein. Species Reactivity:

Human, Mouse, Rat, Monkey, Bovine, Pig

Validation found at provider's website: https://www.cellsignal.com/products/primary-antibodies/gapdh-14c10-rabbit-mab/2118 
GFP trap beads (Cat \#: gta-100, Provider: ChromoTek)

Validation statement from the manufacturer: GFP-Trap ${ }^{\circledR}$ Agarose is an affinity resin for immunoprecipitation of GFP-fusion proteins.

It consists of a GFP Nanobody/VHH coupled to agarose beads.

Validation found at provider's website: https://www.chromotek.com/products/detail/product-detail/gfp-trap-agarose/

GFP (Cat\# sc-9996, Santa Cruz Biotechnology)

Validation statement from the manufacturer: Anti-GFP Antibody (B-2) is a mouse monoclonal IgG2a (kappa light chain) GFP antibody provided at $200 \mu \mathrm{g} / \mathrm{ml}$, raised against amino acids 1-238 representing full length GFP (green fluorescent protein) of Aequorea victoria origin

Validation found at provider's website: https://www.scbt.com/p/gfp-antibody-b-2?productCanUrl=gfp-antibody-

b-2\&_requestid=272661

IRF3 (Cat\# 4302, Cell signaling Technology)

Validation statement from the manufacturer: IRF-3 (D83B9) Rabbit mAb detects endogenous levels of total IRF-3 protein. Species Reactivity:Human, Mouse, Rat, Monkey

Validation found at provider's website: https://www.cellsignal.com/products/primary-antibodies/irf-3-d83b9-rabbit-mab/4302

phospho-IRF3(Ser396) (Cat\# 4947, Cell signaling Technology)

Validation statement from the manufacturer: phopho-IRF-3 (Ser396) (4D4G) Rabbit mAb detects endogenous levels of IRF-3 when phosphorylated at Ser396. Species Reactivity:Human, Mouse

Validation found at provider's website: https://www.cellsignal.com/products/primary-antibodies/phospho-irf-3-ser396-4d4grabbit-mab/4947

IkBa (Cat\# 4812, Cell signaling Technology)

Validation statement from the manufacturer: IkB $\alpha$ (44D4) Rabbit mAb detects endogenous levels of total IkB $\alpha$ protein.Species Reactivity:Human, Mouse, Rat, Hamster, Monkey, Mink

Validation found at provider's website: https://www.cellsignal.com/products/primary-antibodies/ikba-44d4-rabbit-mab/4812

phospho-IkBa(Ser32/36) (Cat\# 9246, Cell signaling Technology)

Validation statement from the manufacturer: Phospho-IKB $\alpha$ (Ser32/36) (5A5) Mouse mAb detects endogenous levels of IkB $\alpha$ only when phosphorylated at Ser32/36.Species Reactivity:

Human, Mouse, Rat, Monkey

Validation found at provider's website: https://www.cellsignal.com/products/primary-antibodies/phospho-ikba-ser32-36-5a5mouse-mab/9246

TBK1 (Cat\# 3013, Cell signaling Technology)

Validation statement from the manufacturer: TBK1 Antibody detects endogenous levels of total TBK1/NAK protein.Species Reactivity:Human, Mouse, Rat, Monkey

Validation found at provider's website: https://www.cellsignal.com/products/primary-antibodies/tbk1-nak-antibody/3013

pTBK1 (Cat \# ab109272 abcam)

Validation statement from the manufacturer: This antibody only detects NAK/TBK1 phosphorylated at serine 172 .Validation found at provider's website: https://www.abcam.com/naktbk1-phospho-s172-antibody-epr28672-ab109272.html

P65(NFkB) (Cat\# 8008, Santa Cruz Biotechnology)

Validation statement from the manufacturer: Anti-NFKB p65 Antibody (F-6) is a mouse monoclonal IgG1 (kappa light chain) NFKB p65 antibody provided at $200 \mu \mathrm{g} / \mathrm{ml}$, raised against amino acids 1-286 mapping at the N-terminus of NFkB p65 of human origin Validation found at provider's website: https://www.scbt.com/p/nfkappab-p65-antibody-f-6?productCanUrl=nfkappab-p65antibody-f-6\&_requestid $=285577$

Lamin B1 (Cat\# sc-373918, Santa Cruz Biotechnology)

Validation statement from the manufacturer: Lamin B1 Antibody (G-1) is a mouse monoclonal IgG3 (kappa light chain) provided at $200 \mu \mathrm{g} / \mathrm{ml}$, specific for an epitope mapping between amino acids 559-586 at the C-terminus of Lamin B1 of mouse origin Validation found at provider's website: https://www.scbt.com/p/lamin-b1-antibody-g-1?requestFrom=search

\section{Eukaryotic cell lines}

Policy information about cell lines

Cell line source(s)

A549 cells $\left(\right.$ ATCC $^{\circledR}$ CCL- $^{185^{\text {TM }}}$ ), HeLa $\left(\right.$ ATCC $^{\circledR}$ CCL-2 ${ }^{\text {TM }}$ ), CaCo-2 (DSMZ, ACC 169)

Authentication

Cell lines were authenticated using STR DNA profiling.

Mycoplasma contamination

All the cell lines used tested negative for mycoplasma.

Commonly misidentified lines (See ICLAC register)

The cell lines used in the study are not in the commonly misidentified lines list. 